\title{
LAS CORRIENTES SUBTERRÁNEAS. UN CASO DE ESTUDIO EN LAS DISPUTAS POR EL BOSQUE EN EL SUROESTE DE LA CIUDAD DE MÉXICO. 1856-1913¹
}

\author{
Romana Falcón \\ El Colegio de México
}

Mas no podemos transitar con leña o carbón, sin que el administrador de la hacienda de Mipulco diga que aquellos artículos son de su propiedad, o el de La Cañada nos recoja el hacha o quite alguna prenda que asegure el pago de la multa; no podemos salir con nuestros ganados fuera del corral [...] sin que uno u otro de los espresados administradores procure recogerlos, imponiéndonos muchas veces la multa de un real por cabeza.

Permiso para litigar de San Nicolás Totolapan, $1872 .^{2}$

os bosques, montes y pastizales, con los muy diversos re-
de los pueblos, haciendas y fábricas desde tempranas épocas de

Fecha de recepción: 16 de julio de 2019

Fecha de aceptación: 21 de octubre de 2019

${ }^{1}$ Agradezco la ayuda de Pablo Kalax Orozco, Juan Manuel Siles y Circe Torres, a quienes cito en orden alfabético.

2 RAN-AGA, San Nicolás Totolapan, Restitución de ejidos, exp. 24/937 (7), fs. 74-77. 
la era colonial. A lo largo de siglos, cuantiosas leyes, así como normas consuetudinarias, trataron de ir reglando los variados derechos de acceso, uso, posesión y propiedad, lo que frecuentemente derivó en contradicciones y vacíos legales. Aun cuando hubo conflictos numerosos y diversos, las siguientes páginas únicamente explorarán las tensiones entre haciendas y pueblos, ${ }^{3}$ no solo porque fueron decisivas para conformar los territorios forestales, sino también porque permiten asomarnos a la historia social y económica de los habitantes humildes, principalmente de aquellas comunidades que poseían recursos forestales. Puesto que el desenvolvimiento de estas querellas no es ajeno al de otras controversias entre actores colectivos y actores particulares que plagaron a todo México durante el primer siglo de vida independiente, es posible que iluminen el acontecer en muchos otros rincones de la joven nación y contribuyan a llenar una laguna historiográfica fundamental: las complejas relaciones entre pueblos y haciendas, que es donde residió, durante siglos, el grueso de los mexicanos.

Lógicamente, hubo enormes variaciones en cada rincón de un país tan extenso y diverso como México, por lo que, para lograr la concreción debida, este artículo se limita al estudio de una zona con densos bosques en el suroeste de la ciudad de México, localizada en la serranía del Ajusco en Tlalpan -donde nace el río Eslava-, así como en la serranía de las Cruces en la cuenca del río Magdalena. El área geográfica por donde transitan estos ríos abarca más de 3000 ha que se localizan en las alcaldías de Magdalena Contreras, Tlalpan, Álvaro Obregón y Cuajimalpa. ${ }^{4}$

\footnotetext{
${ }^{3}$ Los derechos públicos sobre zonas forestales no serán aquí analizados, para empezar por ser relativamente insignificantes en esta región, al menos hasta 1910.

4 Almeida-Leñero, Nava, Ramos, Espinosa, Ordoñez y Jujnovsky, "Servicios ecosistémicos", pp. 55-57. También son afluentes los ríos Hondo, Mixcoac, Barranca de Guadalupe y San Miguel que luego confluyen en el río Churubusco.
} 
Presento las hipótesis que aglutinan este texto y que sirven como guía al lector. Como sucede comúnmente en las investigaciones, estas páginas han ido cambiando de hipótesis central, y conviene señalarlo por las inflexiones que las ideas aglutinadoras pueden tener cuando se mueven los espacios temporales. Un primer hilo conductor de este trabajo propuso que, si bien durante los primeros 90 años del México independiente (18201910) en esta región se experimentaron transformaciones considerables que tendieron a la privatización y a una utilización más intensiva e industrial de los recursos, los usos y derechos del bosque no fueron trastocados de manera radical. Ello, a pesar de los procesos de desamortización y de que las leyes y políticas forestales del porfiriato fueron limitando y mercantilizando los usos tradicionales de los montes, lo que dio pie a múltiples conflictos y resistencias. ${ }^{5}$ En algunos aspectos fundamentales, como la permanencia de los pueblos y haciendas, así como el carácter de sus disputas, hay continuidades desde el siglo xvI.

Claro que hubo tensiones persistentes entre los actores sociales y los privados, muchas de las cuales se evidencian en el material de archivo. Sin embargo, hasta el estallido de la revolución mexicana de 1910, no se advierten alteraciones extremadamente radicales, ni en los conflictos respecto a la leña, la madera, el carbón, el pastoreo y los parajes que se abrían al cultivo, ni en las formas como actores individuales, actores sociales y autoridades buscaban solucionar, o sobrellevar, las querellas. De hecho, en una primera versión de este trabajo, ${ }^{6}$ que tomó como límite temporal el porfiriato (1876-1911), presenté como idea central las

\footnotetext{
5 Ramos, "Formas de conflicto ambiental”, pp. 40-44.

6 Este trabajo se presentó primero como ponencia, "La disputa por el bosque. La mediación entre derechos públicos, privados y de pueblos sobre el río Magdalena, Ciudad de México”, mesa S105. Lo privado, lo común, lo público. Derechos de propiedad, estructura productiva y cambios en el territorio (siglos XVIII-XX), en el II Congreso Internacional XVI SEHA, VII Rural Report. 20-23 de junio, Santiago de Compostela, España, 2018.
} 
notables persistencias en las facultades de propiedad, posesión y usufructo, así como de acceso y tránsito que hacía mucho tenían quienes habitaban estos pueblos, a pesar del ambiente más hostil a los usos tradicionales del bosque. Claro que no era de suponerse una pura y simple supervivencia de antiguas prerrogativas, ni una inmovilidad económica, social, política, religiosa y cultural, pues, como en cualquier sitio, eran precisamente estas experiencias los factores centrales en la transformación del territorio y de la sociedad pueblerina.

Estas ideas se trastocaron profundamente al ampliar el estudio tres años más. Un gran suceso, que desde luego no era inevitable, la irrupción revolucionaria, en especial la rebelión agrarista con epicentro entre los pueblos de Morelos, sacaría a la luz profundas controversias sociales entre comunidades y haciendas que compartían los bosques desde hacía siglos. La revolución de 1910 -la primera revolución social moderna de occidente- cambió, a veces de manera drástica, los derechos sobre los bienes naturales. Además, y ello es igual de significativo, transformó la forma como se veían a sí mismos tanto los vecinos de los pueblos como quienes eran dueños y quienes administraban las haciendas, es decir, los actores centrales de este artículo.

Los dramáticos acontecimientos que se vivieron en esta región durante los primeros años revolucionarios pusieron al desnudo cómo el statu quo solo conformaba un equilibrio inestable, una calma tensa susceptible de quebrarse. Así, una segunda hipótesis que complementa la primera, la que resalta la notable continuidad en los nexos entre haciendas y pueblos, es que, por debajo de las aguas plácidas del statu quo, había corrientes subterráneas de conflictividad que salieron a flote cuando la revolución rompió las compuertas del orden establecido. En casi todo el orbe y, en el transcurrir de los siglos, las revoluciones son hechos sumamente raros. México es, acaso, una excepción porque, con solo un siglo de diferencia, fue sacudido por dos rebeliones sociales. Ríos de tinta han alimentado las controversias 
sobre cómo caracterizar estas acciones, pero nadie duda de su origen multifactorial. ${ }^{7}$

Estas páginas no buscan mostrar las razones de la revolución mexicana en estos territorios, sino llamar la atención sobre cómo agravios antiguos se pudieron expresar con vehemencia y violencia, al romperse los arreglos sociales acostumbrados. Entre las raíces del descontento destacan dos, perfectamente entrelazadas en el tiempo: los derechos diversos por los recursos del bosque, así como los agravios morales y de justicia, en especial el trato que leñadores, carboneros, pastores y otras gentes del común recibían de quienes ejercían su autoridad sobre ellos. Aun cuando, desde ciertas ópticas, se trataba de contiendas comunes y relativamente intrascendentes, meros pies de página del pasado, probaron ser definitivas cuando los agraviados tuvieron los medios para hacerse oír y vengarse.

Es posible que la historiografía mexicanista no le haya concedido la trascendencia debida a un personaje cuya importancia queda en manifiesta mediante esta investigación: el administrador de hacienda, nexo fundamental entre pueblos y fincas, que regía buena parte del trato diario con los del pueblo, así como las mil aristas de los derechos al bosque. Tal y como sucedía desde hacía siglos, el roce de leñadores, pastores, carboneros y otros se escenificaba, no tanto con los dueños, sino con los diversos encargados del mando social. Sus acciones se basaban en determinadas leyes y costumbres que les permitían extender su influencia sobre numerosas esferas.

Conviene hacer aquí una breve introducción al tipo de poderes que podían ejercer los administradores sobre los habitantes de la región, ya que dieron pie a numerosas querellas desde la era colonial y hasta el siglo xx. Estos personajes actuaban, con frecuencia, en colusión con autoridades menores, como jueces locales y corregidores de policía. Entre sus prerrogativas

7 Véase la excelente discusión de Tutino, De la insurrección. 
sobresalía el emitir los “boletos" con que los pobladores pagaban sus derechos en torno a la leña, madera, carbón y pastos, lo que daba pie a conflictos y arreglos sobre el precio y la adquisición de dichos vales. Además -cómo se verá acerca de un convenio signado en 1858- solían determinar cómo, dónde, qué tipos y qué cantidad de recursos podrían extraer. De igual manera, cuántos y con qué árboles se podía elaborar carbón vegetal -el principal energético de la época- que se vendía en los pueblos, cabeceras municipales y mercados del sur de la ciudad de México. Encima, eran decisivos para determinar cuáles y cuántos animales podían llevarse a pastar, qué parajes -si es que algunose podían abrir al cultivo agrícola, lo mismo que a la extracción de otros recursos como hierbas medicinales, comestibles -como maíz, frijol, frutas y papas-, piedras de tezontle, paja y zacatón (que en el porfiriato era económicamente significativo, máxime en la región de Parres en el Ajusco).

Los administradores también eran fundamentales para amonestar y detener a los infractores -reales o supuestos- de los reglamentos y costumbres en torno al bosque, monte y pastizales. A los del pueblo les resultaba especialmente gravoso tener que pagar las multas para que se les devolvieran sus animales e instrumentos de trabajo y, en especial, que se les hiciese prisioneros en las propias haciendas o se les entregara a las autoridades. Desde la era colonial, algunos administradores fueron acusados de tratar de manera humillante y soez a quienes trabajaban el bosque o a sus familiares lo que, como se verá, acabaría por revestir una gran trascendencia.

Además, solían representar jurídicamente a las haciendas y encabezar sus litigios y querellas judiciales. Un ejemplo típico de estas tensiones, que se expondrá con detalle, tuvo lugar en 1872, cuando el pueblo de San Nicolás Totolapan acusó al administrador de la hacienda San Nicolás Eslava de malos tratos y exigió que respetase sus "propiedades y posesión"; que permitiese a sus habitantes sacar madera y leña de los montes; que ya no los 
detuviese arbitrariamente, y que dejase de obstaculizar el nombramiento de representante del pueblo que habían decidido. ${ }^{8}$ Por si fuera poco, quienes mandaban en la vida cotidiana de las haciendas ejercían un control profundo sobre sus trabajadores permanentes y temporales, mismos que solían ser de los pueblos contiguos; determinaban un sinnumero de aspectos sobre sus condiciones de vida, sus labores y prestaciones, así como el orden y "respeto" que debían profesar a la finca. Dada la posición clave que desempeñaban, no extraña que en los papeles viejos con que tejemos la historia se apiñaran, a lo largo de siglos, las quejas en su contra. Esta convergencia de los odios populares -al menos en ciertas partes del suroeste de la ciudad de México- se asemeja a lo que pasaba con los overseers, es decir, los administradores de las pequeñas plantaciones del sur de Estados Unidos en la época de la esclavitud, eslabones vitales de ese sistema extremadamente violento y, a la vez, paternalista. ${ }^{9}$

El presente texto está organizado en cuatro partes. Después de unas pinceladas rápidas para presentar el territorio y los principales hechos del pasado, me adentro en los cambios y continuidades que se experimentaron desde que se cortaron las amarras con España. En tercer lugar, examino un botón de muestra de la enconada y centenaria relación entre un pueblo, San Nicolás Totolapan, y una hacienda, San Nicolás Mipulco (o Eslava), que era, principalmente, un aserradero. Estas páginas terminan con los efectos que la primera revolución social del siglo xx tuvo en la región. Se reconsideran las dinámicas sociales de animadversión que paulatinamente anidaron en los pueblos -la rebatinga por el uso y propiedad de los bosques, así como los malos tratos y controles caciquiles- y que solo salieron a flote con la ruptura del statu quo a partir de 1911.

\footnotetext{
8 AHCM, Municipalidades, Tlalpan, Gobernación, c. 120, exp. 47, 1872.

9 Genovese, Roll Jordan Roll.
} 
Los bosques de las cuencas de los ríos Magdalena y Eslava son, aún hoy, a principios del siglo XxI, trascendentes por su valor ambiental, su alta biodiversidad y por ser la principal fuente de agua superficial de la ciudad de México. Los más de $30 \mathrm{~km}^{2}$ de superficie boscosa que todavía existen incluyen pinos, abies y encinos junto con pastizales, matorrales y algunos manchones de actividad agrícola. ${ }^{10}$ Estos bosques, como puede suponerse, conformaban territorios más grandes y densos en la segunda mitad del siglo XIX. ${ }^{11}$ (Foto 1)

\section{Foto 1}

BOSQUE DE PINOS, ABIES Y ENCINOS

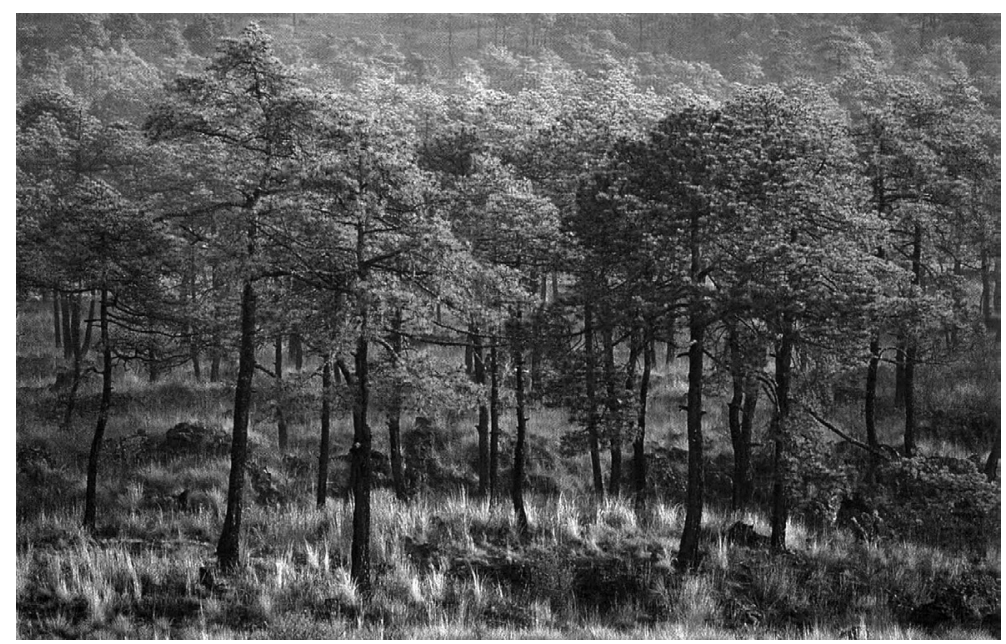

Fuente: Carrillo, El pedregal de San Ángel, p. 101.

10 Jujnovsky, Galván y Mazari-Hiriart, “Zonas Protectoras Forestales”, pp. 65-75.

11 Sales, Flores y Contreras, “La importancia de rescatar”, p. 8. 
Hoy, estas serranías arboladas se localizan, mayoritariamente, en la cañada de Contreras, lo mismo que en la serranía volcánica y accidentada del Ajusco en Tlalpan. Entre los principales pueblos originarios se encuentran San Jerónimo Aculco, San Nicolás Totolapan, La Magdalena Atlitic (más tarde Magdalena Contreras) y San Bernabé Ocotepec, en La Magdalena Contreras; Santa Rosa Xochiac y San Bartolo Ameyalco, en lo que hoy es Álvaro Obregón; San Lorenzo Acopilco y San Mateo Tlaltenango, en Cuajimalpa, así como San Andrés Totoltepec, San Miguel Ajusco, Santo Tomás Ajusco y La Magdalena Petlacalco, en Tlalpan (véase el mapa 1).

La zona fue poblada desde inicios de la era cristiana; hacia el siglo xiv hubo asentamientos mexicas -todavía hoy hay hablantes de náhuatl- así como de tepanecas que acabaron dominados por los primeros, a quienes debieron pagar tributo. De hecho, desde entonces, Totolapan pagaba con madera dichas cargas tributarias. ${ }^{12}$ La guerra fue una constante: aquí se escenificaron batallas de cierto peso durante la conquista española. La población indígena dominó, y para fines del siglo xviII, 84\% de los habitantes eran así considerados. Dadas las condiciones del terreno, estos pueblos estaban habitados por madereros, carboneros, leñadores, pastores y algunos campesinos, además de obreros de las fábricas del textil y del papel asentadas sobre el río Magdalena. Trabajadores fabriles y los del campo solían provenir de las mismas familias y pueblos. Algunos incluso desempeñaban varias ocupaciones a la vez, por caso, carboneros y obreros del textil.

12 Israel Sánchez Pérez, "Historiografía de los títulos primordiales de San Nicolás Totolapan", conferencia en Primer encuentro de estudios sobre San Nicolás Totolapan, Edificio Ejidal San Nicolás Totolapan, 12 de julio de 2019. 


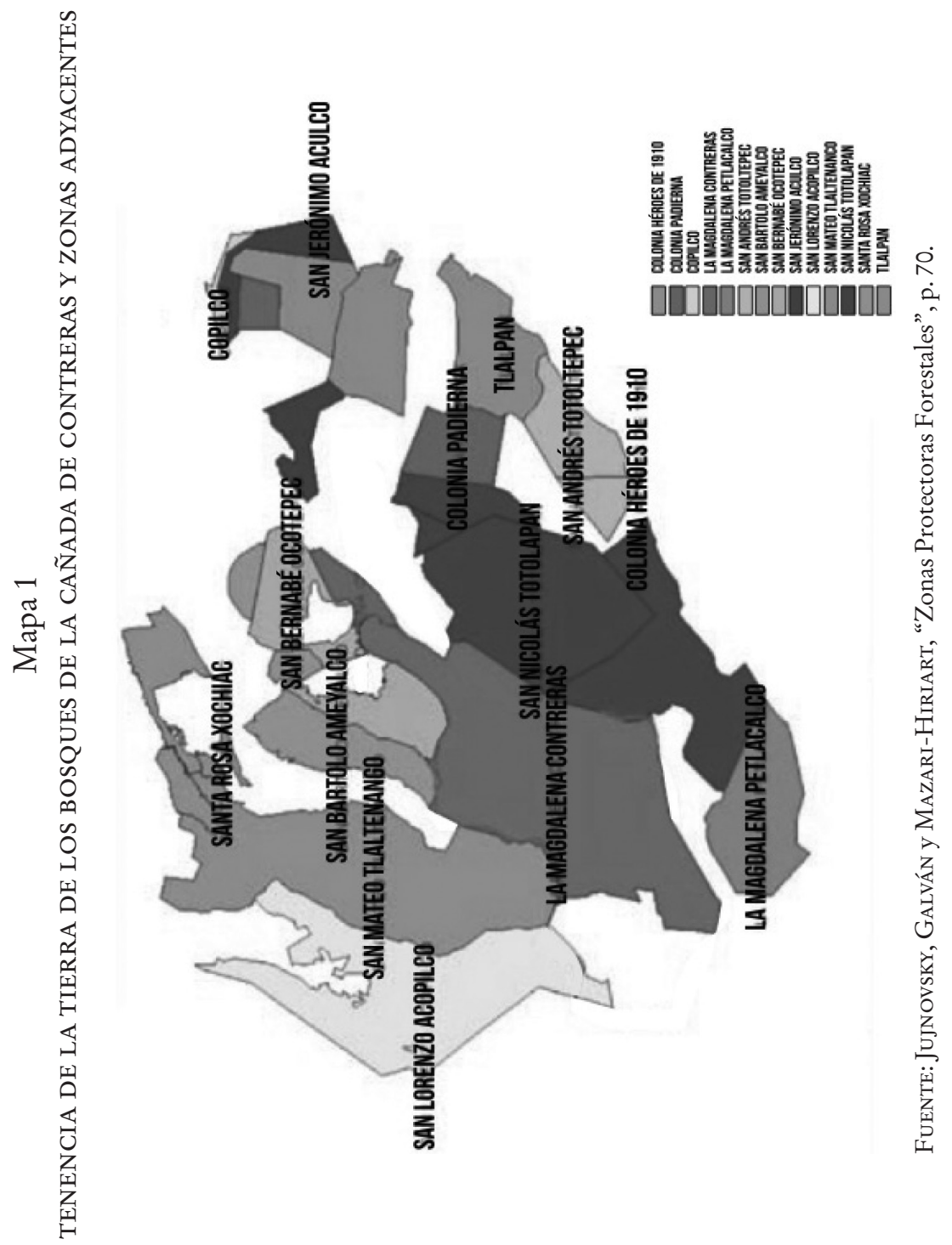


En cuanto a las fincas privadas, a principios de la era novohispana, algunas eran de españoles y otras de caciques indígenas. El primer dominio privado perteneció originalmente al cacique indígena de Coyoacán. Se le llamó Mipulco o Eslava -en ocasiones anteponiéndoles el nombre de San Nicolás-, y sería la principal hacienda de la región a lo largo de siglos. Al inicio medía cuatro caballerías de tierra (172 ha) y desde la era colonial tuvo como vocación la explotación maderera. Experimentó numerosos cambios de dueño y de nombre. También destacaron las haciendas La Cañada, Arenal y Peña Pobre, así como varios ranchos ${ }^{13}$ (mapa 2),

Doy vuelta a la página a fin de mencionar algunas disposiciones novohispanas para regular los derechos de los pueblos de indios puesto que, con frecuencia, en el México independiente se mantuvieron vivas y se adaptaron por autoridades, pueblos y hacendados. Como se comprobará, trozos de ellas quedaron en la memoria popular, cuando así convenía, convirtiéndolas en costumbres y fuentes de legitimidad. Reproduzco por ello algunas disposiciones tendientes a asegurar que los bosques, montes y otros recursos, como el agua, fuesen "comunales" y que los indios accediesen a ellos de manera libre y sin trabas. En 1536 la corona española dispuso que las poblaciones debían estar “[...] abastecidas de pastos y leña según el número de indios y disposición de la tierra, eligiendo los pastos y lugares más convenientes, y no permita que sobre esto sean molestados ni fatigados los indios, imponiendo y ejecutando sobre lo contenido en nuestra ley, las penas convenientes a su arbitrio". ${ }^{14}$

Desde que se dictaron estos derechos respecto de aguas, tierras, pastos y leña, y como sucedía en otros espacios iberoamericanos, muchos pueblos se ampararon en ellos utilizándolos en los siglos por venir. Al mismo tiempo, la corona

13 Percheron, Problemas agrarios, pp. 25, 44-47, 62.

14 Percheron, Problemas agrarios, p. 80. 


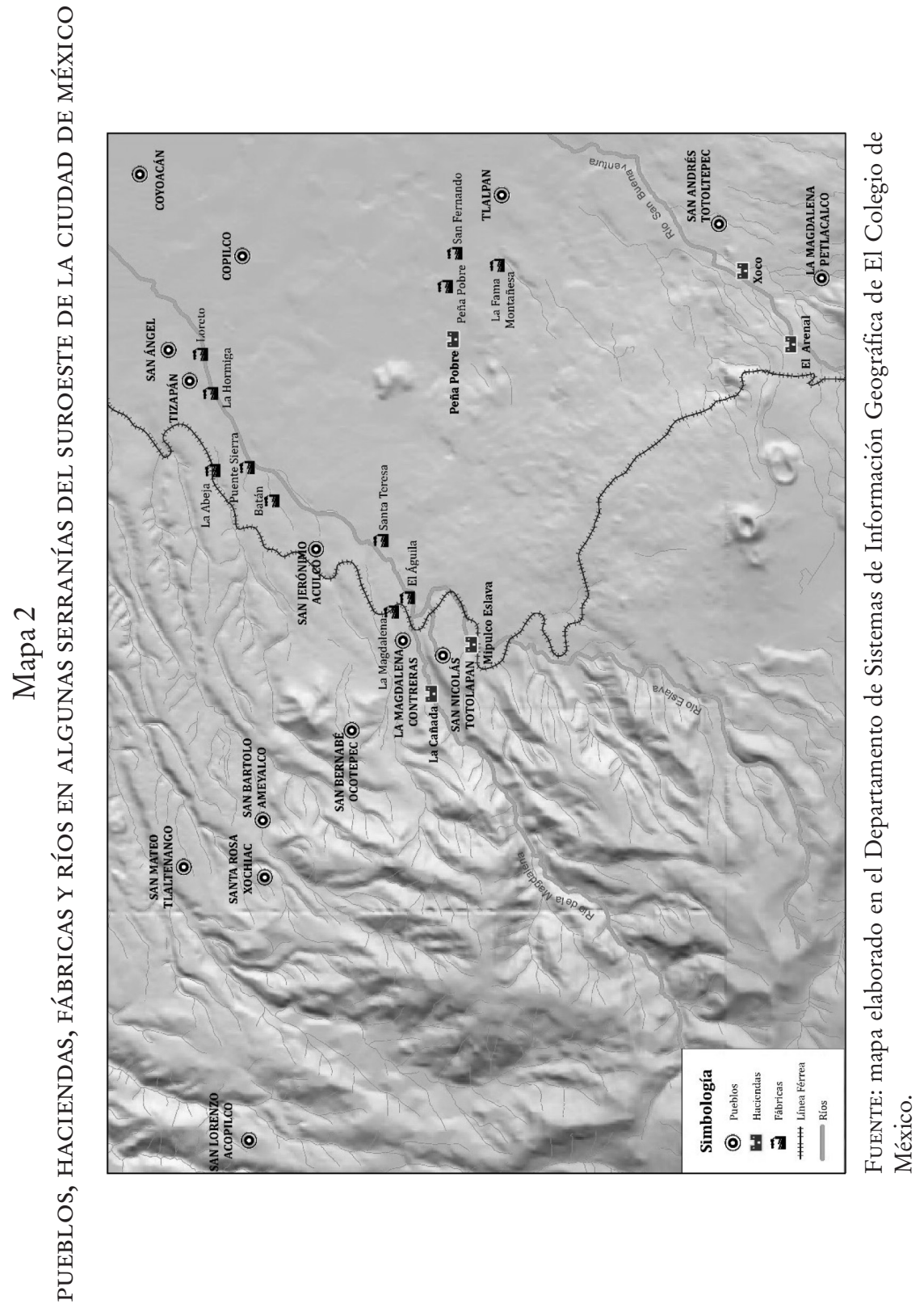


española marcó límites al usufructo que los indios podían hacer para que no lastimasen ni los bienes naturales ni el equilibrio con otros actores sociales. En 1496 los reyes católicos dispusieron, para todos sus dominios: "[...] que los montes [fuesen] comunes para que los vecinos [pudiesen] aprovecharse de ellos, pero cortando las ramas y no los árboles por el pie, dejando horca y pendón para que [pudieran] crecer y reproducirse". ${ }^{15}$

En el siglo XviII se ratificó su capacidad de entrar en estancias y montes para el "corte de todas aquellas especies de leña y maderas que necesitasen para sus propios usos y el de sus familias, fábricas y reparo de su casa y jacales, como también en el de sus iglesias; bien entendidos de que no por este beneficio había de talar, destruir o destrozar los árboles ni causar ningún perjuicio”. Es significativo que esta potestad comprendiera solo "lo necesario y preciso a sus propios usos y menesteres" y castigara a quienes "intentasen vender, o utilizarse en otra forma", ${ }^{16}$ pues se buscaba un equilibrio entre pueblos y hacendados y, por mucho tiempo, en ello se ampararon ciertos propietarios para limitar los derechos de las comunidades sobre el bosque. Un hilo conductor de esta historia atañe, precisamente, a las formas en que todos los actores utilizaban selectivamente aquellos trozos del pasado que les eran útiles para dar cuerpo a sus defensas y legitimidad.

En esta cuenca del río Magdalena la corona otorgó a los pueblos títulos sobre varios territorios, en especial, en tanto bienes comunales de los que tomaron posesión y que incluían amplias superficies boscosas. Desde temprano, estos actores colectivos buscaron asegurar sus derechos mediante títulos, mapas y lienzos que hasta hoy continúan como los documentos fundamentales con que las comunidades "originarias" -término que ahora se utiliza- han defendido sus tierras, aguas y bosques. A su vez, se crearon propiedades particulares dentro de los pueblos,

15 Lira, “Los bosques”, p. 119.

16 Galván, Ordenanzas de tierras, p. 24. 
unas veces de los llamados “terrenos baldíos” otorgados a españoles, mientras que en otras, de las concesiones a los caciques indígenas. ${ }^{17}$ Así, los derechos forestales que durante la era independiente esgrimieron tanto comunidades como privados se fundamentaron en esos antiguos reconocimientos institucionales, en ciertas Leyes de Indias, además de en algunos arreglos consuetudinarios -es decir, normas jurídicas no escritas que se llevan a cabo porque con el paso del tiempo se ha hecho costumbre cumplirlas ${ }^{18}$ que garantizaban el acceso, usufructo y posesión relativamente libres de las áreas forestales.

En muchos rincones novohispanos, entre ellos estas cuencas, surgieron querellas por el haz de derechos sobre bosques y montes. Los hubo entre y dentro de los pueblos, al igual que entre estos y los particulares. Nicole Percheron, en su estudio detallado sobre la serranía del Ajusco, señaló cómo, desde el siglo XVI, las propiedades privadas invadieron recursos comunales, tendencia que sería la base de los conflictos -y sus posibles arreglos- desde la era independiente y hasta la revolucionaria. En 1529 toda esta serranía había pasado a formar parte del marquesado de Cortés en la jurisdicción de Coyoacán. Las disputas no tardaron en aparecer y algunas comunidades rechazaron la pretensión del conquistador y de sus herederos de considerar sus recursos comunales como parte de su marquesado. En principio, la corona amparó a los indígenas: en 1533 una cédula real estableció que "los bosques, las praderas y las aguas eran bienes comunales", y que el marquesado no podía retener su uso exclusivo. ${ }^{19}$

17 Ruiz Medrano, Mexico's Indigenous Communities, pp. 151-184; PercheRON, Problemas agrarios, pp. 71-77, 81-95.

18 Estos arreglos hacen uso de esa costumbre que se desprende de hechos que se han producido repetidamente en el tiempo, en un territorio concreto. https://es.wikipedia.org/wiki/Derecho_consuetudinario. Consultado el 26 de marzo de 2018.

19 Percheron, Problemas agrarios, pp. 82-84. 
Las grandes haciendas -San Nicolás Mipulco (o Eslava), La Cañada, Xoco y El Arenal- buscaron monopolizar recursos forestales. Desde el siglo Xvi algunas se apropiaron, de manera legal o por la fuerza, de bienes de los pueblos, dando pie a querellas y litigios que se agudizaron en el siglo xviII. ${ }^{20}$ Caso extremo fue el pueblo del Ajusco, que perdió las 5000 ha de tierras comunales que se le habían dotado en 1609 y fue cercado por dos fincas privadas: San Nicolás Mipulco y El Arenal. ${ }^{21}$ En suma, los actores principales y sus querellas por el bosque estaban firmemente planteados desde fines de la colonia.

\section{LAS MUCHAS CONTINUIDADES DEL MÉXICO INDEPENDIENTE}

Cuando México comenzó a forjarse a sí mismo, y hasta entrado el siglo xx, la explotación forestal siguió siendo vital para las comunidades del Ajusco, de la sierra de Las Cruces y de la cañada de Contreras. De ahí sus habitantes obtenían un amplio rango de productos: de comida, medicinales, energéticos, de producción económica, y otros. Estos pueblos, al igual que otras zonas de montaña, como las del Nevado de Toluca, explotaban diversos tipos de madera para construcción y combustible, producían carbón -la principal fuente de energía en el campo y la ciudad, para su autoconsumo o para vender en mercados locales y en la ciudad de México- y contaban con territorios para pastar, cazar, sembrar, recoger frutos, verduras, tés y hongos, raíz de zacatón que se vendía como materia prima industrial para la fabricación de cepillo, ocochal o paja de monte para la crianza de aves domésticas y utilizada en la fabricación de adobes de barro; tierra de monte para abono; piedras, tezontle, carrizo y hierbas medicinales, "piñas" de ocote para combustible y adornos, así como para "sangrar los árboles", es decir, extraer su resina. Las

20 Percheron, Problemas agrarios, pp. 70-79.

21 Percheron, Problemas agrarios, pp. 77-81 y104-108. 
fábricas utilizaban aguarrás que se extraía de la resina de pinos y ocotes, lo mismo que leña para convertirla, al generar vapor, en fuerza motriz que moviese sus máquinas. ${ }^{22}$ En estas serranías del suroeste de la Ciudad de México, a principios del siglo XxI, todavía la mitad de la población tiene la explotación forestal como actividad destacada. ${ }^{23}$

Durante las primeras décadas después del corte de amarras con España, en estos territorios arbolados se mantuvieron derechos sobre bienes comunales y particulares, bienes notariados como propiedad privada y otros en posesión, así como derechos de acceso y de usufructo que volverían enredado el devenir de los recursos naturales. Hasta la caída del régimen porfirista en 1910-1911, ni los marcos legales federales, ni los de la ciudad de México, ni los emitidos por las prefecturas a los que perteneció esta región, implicaron cambios demasiado profundos en estos territorios forestales.

Y ello, no obstante que la reforma liberal de mediados del siglo XIX en México -como en casi el resto del mundo de occidente- sostuvo leyes y políticas tendientes al "perfeccionamiento” de la propiedad, en especial las multifacéticas Leyes de Reforma que incluían la trascendental Ley de Desamortización de junio de 1856, que buscó debilitar y eliminar los derechos y bienes corporativos, civiles y eclesiásticos. Originalmente, dicha disposición dejaba relativamente a salvo los bienes del común de las corporaciones civiles, es decir, los pueblos, en donde, como explicaron varios de ellos, bien podían ser tomados en cuenta bosques y montes. En ocasiones, su artículo octavo les sirvió de paraguas en torno a varios bienes. La Constitución de 1857 no mantuvo dicha salvaguarda, lo que creó una notable contradicción. Las maneras tan diversas como se interpretaron y se

22 Ramos, "Formas de conflicto ambiental", p. 34. Para los pueblos del Nevado de Toluca véase Almazán, "Usos, perspectivas y conflictos”, p. 50.

23 Esta afirmación se refiere a la zona del Ajusco. Percheron, Problemas agrarios, pp. 41-44. 
implementaron -o se dejaron de implementar- la Ley Lerdo, la Constitución, así como disposiciones liberales posteriores, han hecho brotar ríos de tinta. Dirimir sus propósitos y alcances ha dado pie a interminables controversias historiográficas aún sin resolver. $^{24}$

Un aspecto vital para comprender las querellas forestales fue la falta de nitidez y las frecuentes transformaciones de los linderos. Las razones eran variadas e iban cambiando. Para empezar, en la era colonial, y parte de la independiente, había dificultades notables para hacer "cuadrar" los mapas con lo que sucedía en el terreno. Lo complicado que resultaba marcar físicamente fronteras precisas se agravaba en geografías accidentadas de esta región. De ahí que, con frecuencia, los mapas y títulos de los diferentes actores se sobrepusieran. Muchas demarcaciones se hacían con base en accidentes naturales como "piedras amarillas salpicadas” según señaló San Nicolás Totolapan, ${ }^{25}$ barrancas y ríos, o bien mojoneras provisionales como zanjas o bardas construidas con piedras volcánicas, palos, adobe y otros materiales. ${ }^{26}$ Sería hasta entrado el siglo xx que, por todo occidente, se empezaron a usar marcas más precisas, como el alambre de púas y otras formas de reconocimiento.

Ahora bien, para explicar estos linderos borrosos también es necesario considerar razones de naturaleza distinta, en concreto, de estrategias sociales. Esta indefinición fue un arma de pueblos y haciendas por igual para ampliar su margen de negociación y "dejar pasar el tiempo". De hecho, la destreza más utilizada por muchos pueblos en el centro del país para obviar límites a sus bienes y derechos era simplemente ignorarlos y seguir

\footnotetext{
${ }^{24}$ Véanse Marino, "La desamortización de las tierras", y Falcón, “Desamortización a ras".

${ }^{25}$ RAN, AGA, San Nicolás Totolapan, Restitución de ejidos, exp. 24/937 (7), fs. 74-77.

${ }^{26}$ ReYna, Haciendas en el sur, p. 43.
} 
utilizando los recursos como siempre lo habían hecho. ${ }^{27} \mathrm{~A}$ los pueblos podía serles provechosa esa falta relativa de demarcaciones, pues solían arrendar y hasta "vender" estos terrenos, ya fuese con el conocimiento del ayuntamiento y la jefatura política o bien mediante arreglos de palabra no formalizados.

Por último, la indefinición relativa del territorio y de los derechos sobre el mismo tenía también que ver con la enorme maleabilidad en el usufructo, denominación y atribuciones que "los hijos del pueblo" tenían sobre sus bienes comunes: se los consideraba de una cierta forma durante determinado tiempo y, más adelante, cuando cambiaban las necesidades, los mismos recursos podían pasar a otras categorías. Lógicamente, esta plasticidad no era única de esta región, sino propia de numerosos distritos rurales mexicanos y latinoamericanos.

Regreso a las disputas sobre los territorios arbolados de estas serranías. Percheron asegura que, en el siglo xix, las tres haciendas principales siguieron acaparando tierras comunales, ${ }^{28}$ pues el bosque era fundamental para su economía. Fincas como San Nicolás Eslava (o nada más Eslava o Mipulco) estaban dedicadas al carbón y a un aserradero que producía tablas para construcción. Además, varias fábricas que se modernizaron utilizaban árboles para sus calderas de vapor y sus telares. Las principales textileras eran La Magdalena, El Águila, La Abeja, La Fama Montañesa, Santa Teresa, Puente Sierra, Batán, La Hormiga, Loreto y San Fernando, además de dos fábricas de papel, siendo la principal Peña Pobre que, hasta el siglo xx, elaboró celulosa con insumos provenientes, entre otros lugares, de esta serranía..$^{29}$ Numerosos conflictos sociales salieron a flote en las décadas de 1860 y 1870 , pues varias de estas fábricas también buscaron controlar

27 Buve, "Caciques, vecinos, autoridades", p. 35, y para el caso del Estado de México, Falcón, El jefe político, pp. 394, 490, 510 y 523.

28 Percheron, Problemas agrarios, pp. 120-122.

29 Trujillo, Operarios fabriles, pp. 50-53; Lau, “Tlalpam: una nueva”, p. 311; Ramos, "Formas de conflicto ambiental”, p. 54. 
el caudal de los ríos mediante obras hidráulicas. ${ }^{30}$ Varias huelgas destacaron entre los primeros grandes movimientos obreros del país. En 1876 plantaron banderas rojinegras los operarios de La Colmena, fábrica de hilados y tejidos de Tizapán; al siguiente año, en la fábrica de hilados de San Fernando por aumento de salarios, así como en La Fama Montañesa, y en 1878 en La Magdalena. ${ }^{31}$ Este clima es fundamental para comprender cómo, en el seno de estas familias y estos pueblos -pues entre sus habitantes se contaban numerosos obreros de estas fábricas-, se creó gradualmente una actitud contestataria que ventiló los agravios a la luz pública.

Antes de cambiar de apartado, hay que recalcar que no todo eran contiendas entre pueblos y privados. Con igual o mayor intensidad, casi todas estas comunidades tenían problemas con otros pueblos respecto a linderos, bosques y aguas. Algunas querellas iniciaron en el siglo XVI y subsisten hasta el XXI, como las que enfrentan a San Nicolás Totolapan con Magdalena Contreras (antes Magdalena Atlitic), ya que comparten una amplia colindancia de territorios boscosos. Además, en ocasiones, todos unieron fuerzas en contra de enemigos comunes o en situaciones graves como las epidemias o los horrores de las guerras. Hubo momentos críticos, como diciembre de 1863, cuando avanzaba la ocupación francesa sobre el Valle de México y el gobierno juarista salía hacia el norte del país; los franceses situaron una fuerza militar considerable en La Eslava y en San Nicolás Totolapan dando lugar a varias escaramuzas con liberales. ${ }^{32}$ También se unían ante enfermedades y emergencias, como fue el gran incendio en el monte de la Eslava en la primavera de

30 Trujillo, Operarios fabriles, pp. 29, 49 y 54-56.

31 González Navarro, “Las huelgas textiles”, pp. 203-204, 207.

32 AGN, Gobernación, Segundo Imperio, Tranquilidad Pública, Prefecturas del Valle de México y Toluca, vol. 16, exp. 13, f. 15, citado en Gayosso, "Catálogo de la sección”. 
1866, que se propagó hasta el Ajusco y que logró ser detenido por los habitantes del mismo distrito. ${ }^{33}$

\section{UN BOTÓN DE MUESTRA: SAN NICOLÁS CONTRA SAN NICOLÁS}

Pongamos ahora la lupa sobre un caso concreto para mostrar la riqueza de los nexos que unían y sobre todo oponían a un pueblo, San Nicolás Totolapan, con la hacienda San Nicolás Mipulco, misma que, reitero, cambió con frecuencia de dueño, límites y nombre, entre otros, San Nicolás Eslava. Desde el imperio español, esta tenía como interés primordial explotar la madera, aunque también cultivaba cereales y exportaba ganadería de bovinos y ovinos. Para el siglo XviII destacaba su producción de carbón vegetal destinada a la ciudad de México y más tarde instaló un aserradero que duraría hasta el siglo xx. ${ }^{34}$

Esta historia tiene raíces profundas, pues algunos episodios novohispanos marcaron las pautas de paternalismo, explotación y complementariedad. También de entonces parten algunos fundamentos legales y de legitimidad de los contendientes. Reseñar la hostilidad entre la hacienda de Mipulco y comunidades colindantes ocuparía numerosas páginas. A pesar de que no todo eran querellas y de que había vías institucionales para paliar las controversias más espinosas, las tensiones se extendieron por siglos y tuvieron numerosas raíces: tierras, aguas, bosques, montes, cuestiones laborales y, también de preminencia, el trato dispensado por los administradores a la gente del común. Ya que

33 AGN, Gobernación, Segundo Imperio, Tranquilidad Pública, Prefecturas del Valle de México y Toluca, vol. 27, exp. 1, f. 43, 4 de mayo de 1866 y AGN, Gobernación, Segundo Imperio, Tranquilidad Pública, Prefecturas del Valle de México, vol. 27, exp. 1, f. 44, 5 de mayo de 1866, citado en GAYosso, "Catálogo de la sección".

${ }^{34}$ La información sobre la era colonial y primera mitad del siglo xix se basa, sobre todo, en Percheron, Problemas agrarios, pp. 89-90 y Reyna, Haciendas en el sur, pp. 39-61. 
estas querellas no debieron ser del todo diferentes a las de otros actores colectivos y privados en muchos rincones de la Nueva España y, más tarde, del joven país, es muy probable que iluminen el acontecer en otros rincones de la nación.

En la década de 1730 el acaudalado irlandés Gerardo Moro adquirió La Eslava junto con otras propiedades del Ajusco y poco tardó en poner cortapisas a los naturales en su abastecimiento de leña, carbón y agua, lo que dificultó su subsistencia. En 1736 una terrible epidemia de matlazábuatl-probablemente tifus o peste y una de las más devastadoras en todo el territorio novohispano- provocó una mortandad notable en la región. Muchos huyeron. Para conservar los brazos requeridos, Moro adoptó una actitud más paternalista: proporcionó médicos, curaciones, entierros y ayudas a las familias de carboneros, arrieros y gañanes. Luego aprovechó para vender a las comunidades contiguas, y a altos precios, sus cosechas, el carbón, la madera y la leña. ${ }^{35}$

Numerosos incidentes de estas luchas por los frutos del monte entre Mipulco y los pueblos cercanos desataron resentimientos contra los administradores. En 1779 Antonio Mendoza, encargado de Mipulco y de nacionalidad española, interpuso un juicio en contra de los naturales de San Nicolás por usufructo de tierras e indemnización de perjuicios. Argumentó que desde hacía años estos solían destruir muchas partes del monte, cortar maderas, tablas y vigas, así como fabricar carbón. Además, habían abierto pedazos de tierra en el paraje de Xacalpa (Xixalpa) para sembrar. Por ello, el administrador embargó los bueyes y los cultivos de los vecinos y detuvo a un par. En el juicio consiguiente, Mendoza acusó al alcalde de San Nicolás -y de paso a otros tres pueblos: Santo Tomas Ajusco, San Miguel Ajusco y

35 Reyna, Haciendas del sur, p. 46. 
San Andrés Totoltepec- de permitir explotar los montes sin el fundamento debido. ${ }^{36}$

Las relaciones laborales llegaron a una crisis a fines del siglo XviII, cuando la hacienda era propiedad del español Manuel Esteban de Enderica. Una vez más resalta el papel del administrador, acusado de destruir diez casas ubicadas en el centro del pueblo para anexar las tierras a Mipulco. Tanto o más definitivo fue que los trabajadores de la finca se quejaron de las penalidades físicas que les infringía el encargado, quien había construido un cepo donde castigaba a los gañanes insumisos. Se trataba de José de Celis, antecesor de otro administrador del mismo nombre, muy probablemente descendiente suyo, que sería muerto por los revolucionarios a principios del siglo xx. Enderica puso manos a la obra para salvar la crisis: destituyó a Celis y nombró a Diego Tejada, desbarató el cepo, aparentemente para que no quedara constancia de su existencia, y utilizó como cárcel La Troje (hoy Casa Vieja, en El Gavillero). Además, se preocupó de aspectos morales: solicitó a sacerdotes de parroquias cercanas que ayudaran oficiando misas los domingos y días festivos en la capilla de la hacienda. Sea como sea, en lo relativo a los usos forestales, el juez amparó a los naturales para que pudiesen explotar el monte de Mipulco en los usos propios de sus casas, familias y animales. ${ }^{37}$ Dado el contexto de la época, en muchas partes de México y del mundo, es probable que lo estricto y, acaso sería más exacto decir, lo brutal de estas relaciones de trabajo se extendiera, al menos intermitentemente, hasta entrado el siglo xx.

Durante el siglo xix, en estas cuencas del Magdalena y del Eslava se mantuvieron muchos hilos del pasado ya que continuaron, básicamente, los mismos actores colectivos y privados que esgrimían estrategias parecidas a las que ya habían

${ }^{36}$ Camacho, Raíz y razón, p. 14; RAN-AGA, San Nicolás Totolapan, Restitución de ejidos, 24/937 (17), fs. 278-299.

37 Camacho, Raíz y razón, pp. 14-15. 
implementado. Además, las autoridades también preservaron varias disposiciones y costumbres coloniales. En cuanto a los nexos de complementariedad entre San Nicolás Totolapan y San Nicolás Mipulco (o Eslava), hubo varios convenios detallados para normar el uso del bosque que compartían y disputaban. El más relevante fue el que se firmó en abril de 1858, ratificado un decenio más tarde y que continuó como punto de referencia en los años siguientes. Sus ocho cláusulas estipulaban derechos, así como restricciones y multas a quienes no se ajustaran a los preceptos. Los naturales del pueblo continuarían

[...] entrando al monte de la hacienda, a sacar leña muerta y a mano para sus usos propios, sin que de ninguna suerte se les impida, podrán entrar con hacha para el mismo objeto, pero presentándose previamente con el administrador, a quien le deberán dar un boleto para que puedan rajar la leña muerta, calculando prudencialmente lo que puedan sacar para el consumo hasta de ocho días, sin poder exigir otro Boleto, hasta que sean pasados, bajo la pena de perder el hacha y la leña, el que saque sin este requisito. ${ }^{38}$

El pastoreo era también relevante. Entregado el boleto al administrador, podrían introducir "en los lugares del Monte que más les convenga, las cabezas de ganado mayor y menor que se espresan en la misma". Los infractores podrían ser "expelidos de la hacienda por sus empleados y sin que los del pueblo puedan por esto, dar queja alguna, se les obligará a pagar los pastos, según costumbre". ${ }^{39}$

38 Convenio de 27 de abril de 1858 sobre Montes y pastos celebrado en la Villa de Coyoacán entre los vecinos del pueblo de San Nicolás Totolapan y el dueño de la hacienda San Nicolás, en RAN, AGA, San Nicolás Totolapan, Restitución de ejidos, exp, 24/937 (6), fs. 154-157.

39 RAN, AGA, San Nicolás Totolapan, Restitución de ejidos, exp. 24/937 (6), fs. 154-157. 
Cabe señalar que muchos de los arreglos corrían por vías menos institucionales. Con o sin convenio, casi todas las haciendas permitían, ¿acaso sería más exacto decir, se veían obligadas a permitir?, el uso de tierras, bosques y pastizales a los pueblos, ya que las que poseían no siempre les bastaban, además de que alegaban -con o sin sustento- facultades pretéritas sobre ellos. Dichos permisos eran condicionados, tanto por reglamentos como por costumbres, y eran particularmente difíciles de negociar en territorios en litigio.

A fin de observar en acción los elementos señalados, centrémonos en una coyuntura crítica: aquella originada por el fin de una larga guerra de intervención (1863-1867) y por los recambios a fondo que significó el triunfo liberal liderado por Benito Juárez. Los momentos de condensación histórica facilitan observar las dinámicas de una sociedad y, en este caso, la profundidad de las transformaciones pues, con el fusilamiento del emperador Maximiliano en el verano de 1867, se esfumaron los sueños imperiales. Los juaristas pudieron empezar a dibujar en la realidad la república moderna y liberal que tanto anhelaban.

Con este profundo sacudimiento y, al menos por unos tres años, todo México fue un hervidero de revueltas políticas, así como de otras agraristas -en especial, la rebelión relativamente cercana de los pueblos de Chalco en el Estado de México-. Esta tuvo lugar en el pueblo indígena de San Francisco Acuautla, municipio de Ixtapaluca; tenía problemas por linderos y uso del bosque con la hacienda de Zoquiapan desde el siglo XviI y fue la cuna de Julio López, el principal dirigente de la rebelión de 1867-1868, cuando los pueblos de Chalco y Amecameca se levantaron primero, contra los hacendados y, más tarde, también del gobierno nacional, encabezado por Benito Juárez, que había desoído sus peticiones y que culminó con el fusilamiento de Julio López y otros de sus principales líderes. ${ }^{40}$

40 Falcón, “Tiempos de guerra”, pp. 175-178. 
Cabe resaltar la proximidad ideológica y organizativa de estos con los del Magdalena. Durante la guerra de intervención francesa, fuerzas antiimperiales de Chalco y del Ajusco mantuvieron contactos político-militares, conjuntaron sus fuerzas guerrilleras que, como tantas otras diseminadas en el territorio nacional, para las autoridades imperiales eran difíciles de controlar y, más aún, de derrotar. Un momento particularmente espinoso fue noviembre de 1863 ya que, como se refirió, no obstante que el gobierno liberal estaba ya refugiándose en la frontera norte de la República, las fuerzas imperiales no alcanzaban un control pleno del Valle de México. De ello da cuenta la desesperación del prefecto imperial de Chalco, quien, ni con ayuda de los subprefectos del sur de la ciudad, lograba exterminar a los opositores refugiados en la sierra del Ajusco. ${ }^{41}$ No es improbable que, un lustro más tarde, cuando en Chalco prendió una profunda rebelión campesina, se mantuvieran algunas de estas redes.

Regreso a estas cuencas y serranías. A fines de 1867, época en que ya se cocinaba la insurrección de Chalco, numerosas discordias comenzaron a destaparse. O los de San Nicolás aprovecharon el impasse que significaba reconstruir la vida pública del país para utilizar más a fondo parte de los bosques en disputa, o bien, la hacienda La Eslava se sirvió de la coyuntura para acusar al pueblo de reapropiarse, indebidamente, de dichos recursos. $\mathrm{O}$, tal vez, ambos a la vez. Al igual que en otros rincones del país, los gobernantes no pocas veces tomaron partido en contra de los campesinos movilizados. ${ }^{42}$ La razón del ataque liberal en contra del pueblo es un enigma, pues todo parece indicar que este siempre estuvo en contra de los imperialistas, e incluso fue incendiado por tropas francesas. En noviembre de 1867 Juan

${ }^{41}$ AGN, Gobernación, Segundo Imperio, Tranquilidad Pública. Prefecturas del Valle de México y Toluca, vol. 15, exp. 18, fs. 11-20, 21 de noviembre de 1863, citado en Gayosso, "Catálogo de la sección".

${ }^{42}$ Falcón, “El Estado liberal”, pp. 1010-1012. 
José Baz, importante juarista que poco después sería gobernador del Distrito Federal, exigió al prefecto y comandante militar de Tlalpan reprimir "el atentado de algunos vecinos del pueblo de San Nicolás, que colindan con la hacienda de San Nicolás Eslava, ocupando e invadiendo sus terrenos y monte”, y pidió "reponga las cosas al estado que guardaban, sin que esto impida el castigar a los culpables". ${ }^{43}$

A partir de este punto, las querellas entre San Nicolás y Eslava se sucedieron una tras otra. Dicha situación es ideal para fines analíticos, pues permite observar la gama de legitimidades que esgrimieron ambos contendientes: elementos de economía moral en torno a sus derechos originales desde la época novohispana, los relativos a leyes vigentes, así como el uso de instituciones modernas del poder ejecutivo y de justicia.

En octubre de 1867 el pueblo solicitó licencia para litigar y la hacienda contraatacó al inicio del siguiente año, al pedirle al juzgado que certificara sus propiedades. El aparato de justicia no quiso comprometerse e intentó regresar las aguas a su cauce. En marzo, "en virtud de que habiéndose suscitado algunas diferencias sobre el uso que hacen los pueblos del monte y pastos de la hacienda y con el objeto de evitar un litigio, convinieron en ocurrir a una junta [...] para un arreglo". Según la finca, los vecinos estaban "en posesión" de los montes y pastos en disputa, aunque "ignoraba de que procedía su derecho de ella". A pesar de los perjuicios que ello supuestamente les significaba, Mipulco propuso regular el ganado del vecindario pues lastimaba árboles valiosos, así como la leña que se llevaban para vender ya que -basándose en costumbres pretéritas-solo debían tomarla "para sus usos propios". Buscaban, pues, fijar el modo "de convivir". ${ }^{44}$ (Foto 2)

43 Orden de Baz, 3 de noviembre de 1867, en RAN, AGA, San Nicolás Totolapan, Restitución de ejidos, exp. 24/937 (6), fs. 157-158.

${ }_{44}$ RAN, AGA, San Nicolás Totolapan, Restitución de ejidos, exp. 24/937 (6), fs. $74-77,154-157$. 
Foto 2

GANADO EN LOS MONTES DE CONTRERAS

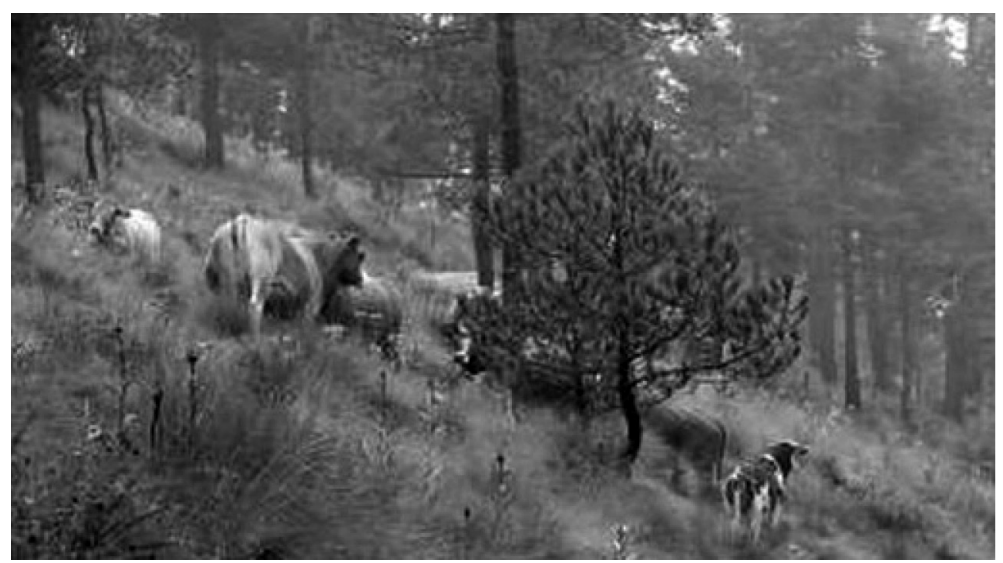

Fuente: Ávila-Akenberg, “Forest quality”, p. 105.

La comunidad refutó estas premisas y, con bastante éxito, exigió mantener algunas facultades pretéritas. El síndico tenía un as bajo la manga: una sentencia del corregidor de Coyoacán, de junio de 1780, que declaraba que:

[...] los indios del pueblo de San Nicolás puedan usar del Monte de la Hacienda de Mipulco, en lo que fuere para los propios usos de sus casas y familias y de los pastos para sus animales, siendo en corto número y con calidades traigan por donde no hagan daño en las sementeras. ${ }^{45}$

Y fue en "virtud de esta Concesión” que, en la primavera de 1868, discutieron "el modo de usar de ella, sin perjuicio de la Hacienda y en beneficio del pueblo”. Aun cuando se ratificó

45 RAN, AGA, San Nicolás Totolapan, Restitución de ejidos, exp. 24/937 (6), fs. 155-158. 
el convenio de diez años atrás, al que se ha hecho referencia, ${ }^{46}$ como tantos otros arreglos institucionales del siglo XIX, este se encontraba prendido de alfileres. Manuel Durana, el administrador de Mipulco, no tardó en demandar en tribunales a "los vecinos" por invadir sus terrenos y montes "cortando y extrayendo madera" y solicitó "castigo a los delincuentes". Como se ha probado repetidamente, los pueblos contaban con amplios repertorios de negociación. En abril de 1868 San Nicolás alegó facultades de propiedad y de posesión en los lugares "en que se les había impedido trabajar” y alegó tenerlos en legítima posesión. Pidió que se le "[...] respetase las propiedades y posesión que tenían en los mencionados terrenos, no impidiese a los vecinos sacasen de los montes de la hacienda la leña y madera que necesitasen para sus usos propios". ${ }^{47}$

Con base en elementos de economía moral los del pueblo siguieron "amarrando navajas" en contra del administrador ya que este coartaba sus aprovechamientos del bosque a pesar de las atrocidades que les acababan de infringir las tropas francesas. Demandaron que no impidiese "ni corte a los vecinos el que saque de los montes de Mipulco la madera y leña que necesiten para sus propios usos y los de sus familias, asi como para la reparación de sus casas y jacales quemado en su mayor parte por las tropas francesas". San Nicolás corrió con suerte, acaso ayudado por la solidez de tales explicaciones.

Como en tantas otras ocasiones, uno de los puntos más álgidos fue el de los agravios cometidos por el administrador: Durana había aprehendido a varios del pueblo que hacían uso de sus derechos a talar madera y sacar leña de terrenos que ambos alegaban como suyos. Es muy interesante la actitud del

${ }^{46}$ RAN, AGA, San Nicolás Totolapan, Restitución de ejidos, exp. 24/937 (6), fs. 154-157.

47 RAN, AGA, San Nicolás Totolapan, Restitución de ejidos, exp. 24/937 (7), fs. 304-318. En algunos expedientes pareciera que el apellido del administrador es Corona. 
sistema de justicia en estos niveles bajos pues, tal cual sucedía en otras instancias, falló en defensa de San Nicolás. La autoridad judicial revisó el caso "con el plano de la hacienda en 1853 para determinar con exactitud los lugares donde los vecinos fueron aprehendidos”, y tras verificar tanto la ubicación del conflicto como la legislación vigente, resolvió que estos tenían derecho a usar el monte de la hacienda para los usos propios de sus casas y familias, puesto que aun cuando no les perteneciera esa propiedad, no perturbaban a la hacienda; en cambio, esta los había aprehendido sin haber probado aún que los parajes en pugna le pertenecieran. También recuperaron disposiciones novohispanas: con arreglo a los autos acordados del 7 de enero de 1744 y del 7 de junio de 1762, el juez de distrito resolvió que el administrador había perturbado a los del pueblo en su derecho de posesión, en tanto que previno a aquel, “amonestándolo seriamente", a no volver a ejercer presiones en su contra: esto es, aprehenderlos por su cuenta, y recomendó que acudiera a la justicia en caso de considerarse agraviado. El pueblo recibió un "amparo de posesión” de los "terrenos en disputa”, lo que impedía a la hacienda obstaculizar "el uso de los derechos" que tenían sobre los montes. ${ }^{48}$ Cabe señalar que para 1872 las instancias superiores -el juez de Distrito y los magistrados del Tribunal Superior- ratificaron lo resuelto cuatro años antes y, además, otorgaron a San Nicolás Totolapan permiso para litigar contra las haciendas de Mipulco y La Cañada. ${ }^{49}$

La maraña de acusaciones y quejas ante jueces, regidores y prefectos, así como algunas resistencias, en especial en aquellos terrenos en que ambos alegaban facultades de posesión, no parecía tener cuartel. Con altas y bajas, prosiguió hasta la caída del “viejo régimen” porfirista. En este largo gobierno, Mipulco se

48 AGN, Archivo del Tribunal Superior de Justicia del Distrito Federal, Siglo XIX, c. 457, 1868; AHCM, Municipalidades, Tlalpan, Gobernación, c. 120, exp. $47,1872$.

${ }^{49}$ AHCM, Municipalidades, Tlalpan, Gobernación, c. 120, exp. 47, 1872. 
ensanchó paulatinamente y alcanzó a ser la más extensa de estas serranías: 4600 ha, monto muy grande para la ciudad de México. Nicolás de Teresa, su dueño durante parte del régimen porfirista, llegaría a ser realmente poderoso, pues un hijo suyo se casó con una hija del presidente. Otro hijo fue fundador del Banco Industrial y Mercantil y la familia sería dueña de las antiguas fábricas textileras de La Fama Montañesa y La Magdalena Contreras. ${ }^{50}$ En lo que siguió del gobierno del general Díaz, la negociación entre San Nicolás y La Eslava ante jueces y autoridades del ejecutivo fue disputada palmo a palmo con victorias y fracasos de ambas partes.

Desde luego, no existía una línea recta in crescendo en las tensiones entre pueblos y haciendas, ni en la República ni en el caso que nos ocupa. El dato relevante por mostrar es que en estos territorios el estallido revolucionario no era inminente ni, menos, necesario. No obstante, a fines del siglo xIx, sí hubo picos en las querellas entre este pueblo y el administrador de Mipulco que, en cierta forma, prefiguran los acontecimientos dramáticos que se desataron con la caída del viejo régimen. Empezaban a mostrarse algunas de las tensiones que normalmente quedaban ocultas.

En 1898 aconteció un momento pico que trazaría una línea recta con el zapatismo en esta región. Dicha tensión aparece corroborada en una carta contenida en el archivo de Genovevo de la $\mathrm{O}$, destacado general zapatista que llegaría a tener una relación cercana con rebeldes y gente de estas cañadas. Dicha misiva entre los hermanos Amaya-quienes más tarde serían líderes de la Revolución en San Nicolás- está fechada en marzo de 1898, y deja constancia de 12 habitantes y trabajadores de la finca que se quejaban de "las arbitrariedades que con ellos comet[ía] constantemente Francisco Medina, administrador de la Hacienda

50 Percheron, Problemas agrarios, p. 161, y Reyna, Haciendas en el sur, p. 64. 
de Eslava y de su hijo Fernando Medina, quien ejerc[ía] como corregidor de policía”.

Aunque muchos de estos agravios se derivaban de los malos tratos del administrador y de las controversias por el bosque, había otras causas de resentimiento, como eran las redes caciquiles entre los encargados de las fincas y ciertos escalones bajos de autoridad local. Este es un ejemplo idóneo para probar dicha idea, así como la continuidad histórica de los argumentos. Los Amaya estaban seguros de que, dado que San Nicolás tenía "sus títulos en regla”, Francisco Medina, el administrador, carecía de atribución para "entrometerse" en su propiedad, y menos para molestarlos continuamente cuando ellos solo ejercían su capacidad para sacar leña y madera. Medina, aseguraban, "le pega a la gente y retiene sus rayas y otras veces los encarcela". Con frecuencia los acusaba de "talamontes" y los confinaba -probablemente en separos de la policía, ¿o acaso en la misma hacienda?-y, para obtener su libertad, les exigía "pagar la multa respectiva". Félix Pérez era un caso concreto que, "por el hecho de haber subido al monte a recoger leña, se [le] extorsiona diciendo que se trata de tala de montes". Había pasado tres días en la cárcel hasta que logró gestionar su libertad con el pago de $\$ 2.50$. A ojos pueblerinos, el administrador tenía "una responsabilidad muy grave", ya que incluso les llegaba a pegar. No obstante que era poco lo que podían hacer, organizaron una junta "para determinar cómo deben conducirse los vecinos y las autoridades para evitar un conflicto". ${ }^{51}$ Un decenio más tarde la Revolución les abriría vías expresas para enmendar estos agravios.

Tales odios se confirmaron unos meses después en el conflicto entre Apolinar Muciño, un guardabosque y residente en San Nicolás, y el administrador de Eslava, caso que corrobora una causa principal de por qué estos personajes condensaban la animadversión popular: sus capacidades para tejer redes de

$\overline{51}$ AGN, Genovevo de la O, c. 11, exp. 1, fs. 5-6, 16 de marzo de 1898. 
poder con diversos personajes del gobierno local, lo que, sobra decirlo, potencializaba su dominio y su soberbia. Como se verá, esta condición traería consecuencias graves para algunos de los involucrados.

Paso a reseñar esta querella por voz del guardabosque que habitaba en San Nicolás: el 5 de septiembre 1898, este subió a los bosques de la hacienda por su "necesidad de una poca de leña para el gasto ordinario de mi casa [...] estando así la leña en el monte de la hacienda de Eslava por el derecho que nos concede a los vecinos de este pueblo la ejecutoria que obra en nuestro poder de sacar madera y leña muerta para nuestro uso común", entonces tuvo un altercado con Fernando Medina, hijo del administrador y quien formaba parte de la policía local. Medina "me cogió el hacha sin poner resistencia de mi parte por no perder el derecho", un tipo de acusación que, por cierto, era exhibida con frecuencia en épocas coloniales. Al día siguiente, al darle parte a su padre Francisco Medina, quien no solo era el administrador de la hacienda sino, a la vez, regidor del ayuntamiento, este secundó a su hijo y enfrentó al guardabosque con insultos. Apolinar Muciño se quejó ante el ayuntamiento:

[...] su contestación fue decirme que era yo un bandido en compañia de todos los vecinos del pueblo de San Nicolás y otros insultos bastante ofensivos a mas que ya no ponía el visto bueno al parte que rindo [ $\dot{e}$ ?] hasta nueva orden porque [el administrador] ya había dado parte personalmente a la jefatura de que el guardabosque era un sinvergüenza bandido de primera clase [...].

El administrador aprovechó su doble ocupación en la finca y en el ayuntamiento por lo que, al destituir a Muciño, este último se quejó con el presidente municipal. Dijo que

[...] estaba o quedaba suspenso de mi empleo, y como el señor

D. Francisco Medina de quien he recibido tantos improperios es 
regidor deseo saber si está autorizado para destituirme del empleo que me ha conferido el $\mathrm{H}$. Cuerpo Municipal y autorizado por usted que lo preside suplicándole respetuosamente se digne hacérmelo usted saber para estar entendido y exijo al señor Medina me pruebe que soy bandido $[\ldots] .^{52}$

Ignoro el resultado de esta denuncia, pero consta que el guardabosque fue apoyado por el sistema local de justicia. Ese mismo día, el presidente municipal informó al Juzgado Auxiliar de San Nicolás Totolapan su protesta por "el indecente trato" que recibían del administrador:

[...] ya como autoridad Municipal hostiliza y veja dichos vecinos para los despojos de maderas que sacan del monte de este pueblo, diciendo que es madera robada de las fincas que administra, y que todos los vecinos de este pueblo son bandidos sin excepción de nadie y demás insultos soeces que dicho señor tiene por costumbre proferir contra este vecindario $[\ldots]^{53}$

El pueblo “amarró navajas” y acusó a Medina de insultar a las autoridades de justicia. Domingo Gamboa, el juez auxiliar, afirmó que todos "los jueces de este pueblo" eran "unos pendejos e insulpadores [sic] cosa que dicho señor no es capaz de probar, y $[\ldots]$ continuamente amaga a este pueblo con privarlo de los derechos que por justicia les corresponden". ${ }^{4}$

Cientos de estos agravios debieron haber tenido lugar a lo largo y ancho de México, y en estas serranías de las Cruces y del

52 Énfasis mío. Carta de Apolinar Muciño al Presidente Municipal. AHCM, Municipalidades, San Ángel, Tierras, c. 2, inv. 300, exp. 13, 6 de septiembre de 1898.

53 Carta de Apolinar Muciño al Presidente Municipal. AHCM, Municipalidades, San Ángel, Tierras, c. 2, inv. 300, exp. 13, 6 de septiembre de 1898.

54 AHCM, Municipalidades, San Ángel, Tierras, c. 2, inv. 300, exp. 13, 6 de septiembre de 1898 . 
Ajusco, sin causar revuelo pues, vistos en el contexto citadino o del país, eran relativamente menores; aunque no para quienes los experimentaban. Su memoria sería definitiva cuando una conjunción de factores permitiría lo que es sumamente excepcional en casi cualquier país: una revolución social. Este hecho insólito, detonado en 1910, permitiría que las viejas querellas cobraran vida. Entre muchos otros cambios fundamentales, los de los pueblos pudieron hacer y reclamar lo que antes solo podían decir comedidamente, o de plano callar.

\section{LA VIOLENCIA REVOLUCIONARIA. 1911-1913}

Conflictos, resistencias, negociaciones y arreglos institucionales por bosques, montes y pastizales se mantuvieron activos en estas serranías arboladas. A fines de 1910 Francisco I. Madero llamó a la insurrección y al año siguiente el viejo general oaxaqueño salió exilado, lo que dio inicio a una década terrible de guerras civiles, pero también de apertura y explosión de demandas y ajustes sociales.

Los revolucionarios de Morelos se hicieron presentes desde 1911 en los pueblos de la cuenca del río Magdalena y en la del Eslava. Sus filas se nutrieron con habitantes de San Nicolás, La Magdalena, San Bernabé, San Jerónimo, Ajusco, entre otros. Ciertos autores aseguran que, desde el inicio, la gente del lugar era simpatizante zapatista y le dio todas las facilidades, en especial comida y refugio. ${ }^{55}$ Sin duda, eso debió ser el caso entre algunos comarcanos -cuyo número crecía-, mas no de todos. Para empezar porque solo poco a poco se dieron a conocer las demandas del movimiento suriano, en especial su icónico Plan de Ayala, del 25 de noviembre de 1911, bajo el lema de "Libertad, justicia y ley". Como es sabido, este habló en nombre de "los pueblos oprimidos" y propuso una reforma agraria

${ }_{55}$ López, “La llegada”, pp. 245-246 y 248. 
expedita: “[...] que los terrenos, montes y agua que hayan usurpado los hacendados, científicos o caciques a la sombra de la justicia venal, entrarán en posesión de esos bienes inmuebles desde luego, los pueblos o ciudadanos que tengan sus títulos correspondientes $[\ldots]{ }^{\prime}{ }^{56}$

No es difícil imaginar que estas ideas encontrarían eco entre numerosos habitantes de tales territorios arbolados que, por decenios y hasta centurias, habían defendido legitimidades semejantes.

Para 1912 ya se registraban constantes encuentros con zapatistas en el sur de la ciudad capital, aunque en estas zonas boscosas y en estas tempranas etapas aún era difícil precisar el apoyo a los revolucionarios. Primero, porque este término solía usarse por autoridades y clases altas de forma derogatoria equiparándolos a "bandidos"; y de estas referencias están repletos los archivos oficiales. A su vez, algunas tropelías de fuerzas federales eran encubiertas achacándoselas a supuestos zapatistas. Encima, ciertos delincuentes se presentaban a sí mismos, sin serlo, como seguidores del movimiento morelense. Más significativo es que, como cualquier comunidad humana, los pueblos estaban divididos por clases, religión, identidad y otras fracturas, por lo que no había apoyos ni rechazos totales, ni al movimiento suriano ni a los gobernantes.

Hasta quienes más tarde destacarían como dirigentes zapatistas -en concreto, los hermanos Filemón y Gregorio Amaya de San Nicolás Totolapan- mostraron cómo se utilizaba el término “zapatismo" por autoridades y caciques lugareños para "sacar raja” de esta compleja situación. En una carta de abril de 1912, los Amaya aseguraron que eran los del destacamento en Contreras, junto con notables lugareños, precisamente como el juez de paz, Anselmo Villavicencio, y su secretario Rafael

56 "Plan de Ayala”, en especial art. 6 y 7, 28 de noviembre de 1911, en MagañA, Emiliano Zapata, pp. 79-84. 
Gaitán, quienes acusaban de ello a cualquiera "al que se les pone, al que le parece [...]" para que los aprendiesen haciendo "venir tropas en balde". De hecho, ya se habían llevado a muchos a los que Villavicencio simplemente les tenían "mala voluntad". Gregorio aseguró a su hermano que aquí los zapatistas "[...] ni se conocen, ni se oyen mentar, que se trata de los campesinos que suben al monte, los que trabajan en la Hacienda de Eslava y van al pueblo del Ajusco por paja, raíz, papas, etc. Que se les menciona para cubrir los abusos de los mismos federales [...]" ${ }^{57}$

Sea como sea, no hay duda de que a lo largo de la lucha revolucionaria buen número de residentes en lo que hoy es Tlalpan, Contreras, Álvaro Obregón y Cuajimalpa ofrecieron apoyo logístico, comida, armas y, más aún, se incorporaron activamente a las filas zapatistas. Pelearon como guerrilleros, primero en contra de los federales porfiristas; más tarde se enfrentaron al gobierno usurpador encabezado por Victoriano Huerta y, posteriormente, en la medida en que Venustiano Carranza se imponía sobre las facciones más populares de la Revolución -básicamente la zapatista y la villista-, lo enfrentaron con las armas, aunque eventualmente estos grupos fueron derrotados por los carrancistas.

En vista de que este artículo concluye en los primeros años de la Revolución, conviene precisar cuáles fueron las coyunturas críticas que fomentaron la insurrección en estas serranías. Gente de estos pueblos, como tantos otros de toda la República, fueron afectados por las decisiones, primero del gobierno de Francisco I. Madero y posteriormente del de Victoriano Huerta, de aumentar el reclutamiento militar que, si bien formalmente conservaba las pautas antiguas de un sorteo justo, en numerosas ocasiones se trataba de situaciones forzadas, ${ }^{58}$ es decir, la famosa leva.

57 AGN, Genovevo de la O, c. 1, exp. 2, f. 24, 2 de abril de 1912.

58 López, “La llegada”, p. 245. 
Otra medida gubernamental que ejerció presión sobre la gente del común giró en torno a los intentos de Madero y Huerta de acabar con el zapatismo mediante la toma de las riendas militares y políticas de las principales ciudades y haciendas morelenses pues, en respuesta, el movimiento campesino se atrincheró y se fortaleció en las zonas periféricas montañosas, como eran los cerros del Ajusco y de Contreras, en donde resultaba más difícil que llegasen las unidades del ejército federal, de ahí que se convirtieran en bastiones estratégicos. ${ }^{59}$ En este contexto, controlar las vías férreas que pasaban por tal zona boscosa resultó imprescindible, tanto para que las autoridades dominaran el acceso a Morelos, como para que los revolucionarios se defendiesen, o bien, estorbasen o ayudasen a tomar las riendas de la capital del país. Las paradas que hacía el ferrocarril a partir de la capital de Morelos, es decir, Cuernavaca, eran El Parque y Alarcón, Tres Cumbres (Tres Marías), para luego enlazarse con las estaciones de la ciudad capital: La Cima, Parres, Ajusco, Eslava -en donde entraba en el astillero de esta hacienda, cargaba carbón y leña, y luego proseguía su camino hacia la estación de Contreras-, El Olivar, Mixcoac, Tacubaya y Santa Julia. Por ello, el Ejército Libertador del Sur buscó asentar destacamentos y tender lazos con la gente del lugar que muchas veces le daba facilidades de comida, refugio e información. ${ }^{60}$

Aquellos de esos pueblos que apoyaron con las armas al Ejército Libertador del Sur se coordinaron con el general morelense Genovevo de la O, así como con los generales Francisco Pacheco y Manuel Palafox. Además, tuvieron sus propios líderes: de La Magdalena Atlitic, Vicente Navarro Camacho, y de San Nicolás, Valentín Reyes, Pablo Vértiz, los hermanos Amaya y la familia de Julián Gallegos, cuyos hermanos fueron de los primeros "en alzar a la gente para el monte". Como sucede con

59 Ávila espinosa, Breve historia, p. 93.

60 López, “La llegada”, p. 246. 
frecuencia con los líderes populares, por caso con Emiliano Zapata, algunos heredaban de sus familias cierta tradición de liderazgo. Tiempo atrás, el padre de los Gallegos había enfrentado al administrador de La Eslava y había sido de aquellos vecinos escogidos de San Nicolás a los que se les daba la enorme responsabilidad de guardar celosamente los títulos primordiales del pueblo que databan del siglo xvi. Esta familia, como muchas otras de la zona, había crecido "en el dominio de la Eslava y en un caciquismo que se había consolidado en el pueblo, aliados al administrador y al dueño de la hacienda". El principal señalado era Anselmo Villavicencio, personaje central de esta trama. ${ }^{61}$

Los zapatistas fueron echando raíces en estas serranías y un puñado llegó a formar parte de la guardia personal de Emiliano Zapata. Navarro Camacho fue general del ejército sureño y tuvo con Zapata una cercanía especial. Por otro lado, hubo un campamento zapatista estable en el Pedregal y, para 1914, las facciones revolucionarias de cuño popular presionaron sobre la ciudad capital -la que incluso tomarían a principios de diciembre-; la Brigada Gallegos estableció su campamento en San Nicolás Totolapan, desplazándose desde Anzaldo hasta San Jerónimo. Algunos de estos sitios rebeldes llegaron a ser tan estables que celebraban misas para los soldados revolucionarios.

Entre 1912 y 1918, es decir, para cuando el gobierno ya constitucional de Carranza había logrado un control notable sobre el país, se vivieron en todo México épocas de miseria, enfermedades y enfrentamientos constantes entre federales y revolucionarios. Como toda guerra civil, en estas zonas boscosas, la gente del común padeció altos costos. Hubo buen número de encuentros en el campo, pueblos, haciendas y fábricas; voladuras de las vías de tren y de las fuentes de energía eléctrica; incendios de chozas y casas cometidos por casi todos los contendientes; dislocación de mercados y hambre. Los asesinatos

${ }^{61}$ Camacho, Raíz y razón, pp. 30-32. 
de guerrilleros, así como de quienes defendían las estructuras prevalecientes, o simplemente vivían en la zona, eran el pan de cada día. Entre 1913 y 1915 la violencia tomó su más alto costo con zapatistas fusilados y colgados en las calles como escarnio público y, en respuesta, fusilamientos de federales y de ciertos encargados de las fincas. También hubo matanzas por simples odios personales que poco tenían que ver con la lucha de facciones. Muchos, entre ellos los vecinos "pacíficos" con todo y sus familias, tuvieron que abandonar sus casas y comunidades. Algunas haciendas y fábricas fueron asediadas por los revolucionarios -aparentemente, en 1914 La Eslava fue incendiada por zapatistas- e incluso ocupadas -como la fábrica textil de Santa Teresa, asentada sobre el río Magdalena-. En ese mismo año, y según acusación de huertistas, los zapatistas incendiaron el pueblo del Ajusco. Por su parte, los federales hostigaron comunidades como Topilejo -en la frontera con Morelos- e incendiaron el pueblo de La Magdalena en 1914. ${ }^{62}$ Otro sitio de la cuenca del Magdalena donde la Revolución trajo consecuencias de peso fue San Bernabé Ocotepec, pues las tropas federales hicieron ahí su cuartel general, lo que obligó a muchas familias a emigrar a comunidades cercanas como San Jerónimo, La Magdalena, San Ángel, San Nicolás y San Bartolo Ameyalco. Al terminar la década más violenta, varias de ellas ya no regresaron y algunos "avecindados", de dentro y fuera del pueblo, aprovecharon para quedarse con las casas y terrenos de los que se fueron. ${ }^{63}$

Regreso al hilo conductor de este artículo: la pugna entre San Nicolás Totolapan y San Nicolás Eslava, para insistir en que, como en muchos otros rincones del territorio nacional, al romperse la "paz social" salieron a flote las antiguas querellas.

62 Camacho, Raíz y razón, p. 55, y AGN, Emiliano Zapata, c. 5, exp. 1, f. 160, 19 de febrero de 1915. General Porfirio Bonilla al Cuartel General del Sur, Contreras.

63 Levario, "San Bernabé Ocotepec”, p. 6; AHDN, XI/481.5/96, c. 41, f. 915, 12 de julio de 1914. 
En el tropel de acontecimientos, las pugnas centenarias por los recursos naturales se entrelazaron con el odio hacia los mandamases locales: algunos administradores de haciendas, jueces de las localidades y caciques de escala menor.

Para 1913 las rencillas llegaron al rojo vivo. El personaje que más acaparaba la animadversión era Anselmo Villavicencio, juez de paz desde 1891 y quien había extendido las típicas redes caciquiles. Pertenecía a una familia relativamente pudiente, dueña del rancho Tlacoxcalco, y era muy cercano al administrador de La Eslava. Los odios que hizo nacer se notan en la correspondencia entre los hermanos Amaya, de quienes se ha hablado. En una carta signada en las postrimerías porfiristas -junio de 1909- Gregorio y Filomeno Amaya se quejaban de este personaje, así como del juez auxiliar, Pablo González, quienes, aseguraban, acostumbraban embriagarse y agasajar a las autoridades locales, a los jefes rurales y "gendarmes de los destacamentos, cometiendo muchos desmanes". ${ }^{64}$

La correspondencia entre estos hermanos en enero de 1912, ya en plena guerra entre el zapatismo y el gobierno de Madero, vuelve a mostrar contrariedad por los múltiples abusos de dicho juez, en esta ocasión junto con su secretario Rafael Gaitán, el comisario del pueblo y otras autoridades locales. Los Amaya repasaban con cólera las múltiples arbitrariedades de Villavicencio y "compinches" en contra de los de San Nicolás, La Magdalena y San Bernabé. ${ }^{65}$ La tensión aumentó para la primavera ya que, como se señaló, se acusó a Villavicencio de colusión con los federales en agravio de los pobladores y de los trabajadores de La Eslava. La acusación de "zapatistas" les servía para deshacerse de sus enemigos o malquerientes además de encubrir los atropellos de los mismos federales. "Se dice que han aprendido

64 AGN, Genovevo de la O, c. 11, exp. 1, fs. 16-17, 8 de junio de 1909.

65 AGN, Genovevo de la O, c. 1, exp. 2, fs. 3-4, 8 de enero de 1912. 
[sic] a muchos zapatistas, pero más bien es a quien ellos quieren o le tienen mala voluntad". ${ }^{66}$

Estas animadversiones, ya muy personalizadas, se entretejieron con los agravios agrarios. Tan solo un mes más tarde, en mayo de 1912, la hacienda La Eslava fue amenazada por una nutrida partida de zapatistas o campesinos que, en su mayoría, eran de Totolapan, Ajusco y Contreras, ante la cual José Celis, su administrador, solicitó ayuda a las autoridades de la capital. ${ }^{67}$ No consta, pero es probable, que llegase dicho apoyo. Como sea, la tensión aumentó, y en este río tan revuelto se avivaron también las pugnas entre pueblos; por caso, el añejo problema entre Ajusco y Jalatlaco por límites e invasión de tierras. ${ }^{68}$

Mayo de 1913 fue un momento de condensación histórica en el país y en estas serranías. México estaba en ebullición pues, después del asesinato artero del presidente Madero y de su vicepresidente, perpetrado en febrero de ese año, el general Victoriano Huerta intentaba instaurar su gobierno usurpador mediante una militarización a fondo de todo el país. Al mismo tiempo, se iniciaba el llamado a derrocar al huertismo por parte de los defensores de la constitución al mando de Venustiano Carranza, gobernador de Coahuila.

Localmente se llegó a extremos. Acaso la raíz más profunda, como se ha señalado, era la pugna entre el pueblo y la hacienda por los terrenos forestales. Este contrapunto alcanzó un momento álgido el 13 de mayo de 1913 cuando el Departamento de Bosques de la Secretaría de Fomento -encargada de controlar los recursos del bosque desde un punto de vista más "científico"emitió un dictamen negativo sobre la queja que había levantado el pueblo en contra de Eslava por invasión de lo que consideraba sus terrenos. Ello parecía agotar, al menos por un tiempo, las

${ }^{66}$ AGN, Genovevo de la O, c. 1, exp. 2, f. 24, 12 de abril de 1912.

67 CAMACHO, Raíz y razón, p. 28.

${ }_{68}$ AHCM, Municipalidades, Tlalpan, Tierras, c. 318, exp. 38. 
vías institucionales de esta lucha centenaria. La resolución asemejaba a aquella emitida, décadas atrás, en 1866. En 1913 estas autoridades concluyeron que "[...] por todo lo expuesto queda demostrado que los montes que posee actualmente la Hacienda de Eslava no están amparados por los títulos de San Nicolás Totolapan ni existe la invasión de que se quejan los habitantes". ${ }^{69}$

Fue como una chispa en un charco de gasolina. Más aún porque en algunas regiones de Morelos se empezaba a promover la restauración de tierras que los pueblos consideraban habían sido usurpadas por las haciendas.

Para acabar de formar la "tormenta perfecta" el ejército federal se debilitó justo en esta zona de litigio. Huerta encargó las operaciones en contra del zapatismo al general Juvencio Robles, tristemente famoso por sus excesos en contra de los revolucionarios y por los asesinatos en masa que llegó a cometer en varios puntos de la República, entre otros, en las serranías de relevancia estratégica. El 17 de mayo, Robles informó que Francisco Pacheco - general zapatista al que él llamaba "cabecilla"- estaba bien posicionado en la zona, por lo que le era cada vez más costoso que los trenes militares siguiesen cuidando al de pasajeros, protección que solían hacer justo hasta la estación de Eslava. En vista de que ello le ocasionaba "trastornos en las operaciones por tener que distraer tanto tiempo, trenes y fuerza", dejaría de cuidar esta estación. ${ }^{70}$ Tal decisión dejó en extrema debilidad a quienes antes mandaban en la zona, situación que probaría ser funesta para ellos.

Exactamente ese mismo 17 de mayo de 1913, tan solo cuatro días después del fallo negativo que recibió el pueblo respecto a sus bosques, brotaron a la superficie las corrientes subterráneas de resentimiento contra los más claros representantes de las viejas estructuras. Sigamos una cuidadosa crónica sobre el pasado de San Nicolás. En la medianoche, mediante una acción

69 AGN, Fomento, Bosques, c. 37, exp. 22, 11 fs., 13 de mayo de 1913.

70 AHDN, XI/481.5/88, f. 289, 17 de mayo de 1913. 
combinada de gente de los pueblos y de revolucionarios, se selló el destino de Villavicencio y del administrador de La Eslava.

Reunidos vecinos y zapatistas avanzaron sobre la casa de Villavicencio, y por el camino real a Eslava se lo llevaron a la hacienda. Al arribar a la hacienda, Anselmo gritaba acobardado y desesperado a José Celis que saliera. Al oírlo su compadre, el administrador, se escondió en la casa principal. Los zapatistas entonces derribaron la puerta y lo sacaron arrastrando. Esa noche, ambos fueron colgados en la Hacienda de Eslava [...] junto a la casa principal. ${ }^{71}$

En la mañana, los perpetradores dejaron La Eslava hacia La Magdalena, pero el comisario ya había desaparecido. De inmediato, 70 gendarmes de la montada fueron enviados para vigilar poblados y haciendas del rumbo. En esta enorme tensión, y al tiempo en que el zapatismo crecía, se suscitaron conflictos entre gendarmes y guardias de la hacienda. ${ }^{72}$ Había muchos otros puntos de ebullición: en julio de 1913 los obreros de la fábrica Santa Teresa estallaron una huelga por mejoría de sueldos. Al siguiente mes, los federales llevaron a cabo una expedición contra zapatistas hasta La Eslava, en la que también tomaron parte empleados y el encargado de la finca. El principal encuentro se dio en Chichicaspa y en ese hecho fue muerto Francisco Miner, el español que hacía poco había asumido como administrador de La Eslava. ${ }^{73}$ El ministro de España reaccionó de inmediato y exigió al gobierno de Huerta castigar a los "responsables del asesinato” del súbdito español. ${ }^{74}$ Representó una de tantas otras peticiones de este y otros países en la era revolucionaria.

71 CAMACHO, Raíz y razón, pp. 32-33.

72 Camacho, Raíz y razón, pp. 33-34.

73 AHDN, XI/481.5/88, ff. 389-394.

74 AGN, Gobernación, Periodo Revolucionario, Correspondencia con Secretarias, Secretaría de Relaciones Exteriores, c. 200, exp. 259, 6 fs. 12 de agosto de 1913. 
Así pues, fue hasta que cayó el antiguo statu quo cuando pudieron brotar, y de manera por demás dramática, los viejos odios personales y reclamos por el bosque que enfrentaban a San Nicolás contra Eslava. Fue la Revolución lo que forzó un cambio fundamental en el uso y propiedad de los bosques y montes que por siglos habían estado en disputa. Eslava acabaría por prácticamente desaparecer y sus terrenos fueron a parar a cuatro ejidos de pueblos colindantes mediante los procedimientos de dotación y ampliación de ejidos: en primer lugar, San Nicolás Totolapan recibió 2600 ha; La Magdalena Petlacalco 622 ha, San Andrés Totoltepec 548 ha, además de Padierna que obtuvo $374 \mathrm{ha}$. A la antiguamente poderosa finca solo le quedaron que, en la década de 1970, pasarían a ser parte de la expansión urbana de la ciudad de México. Otra gran perdedora fue La Cañada pues, con base en sus terrenos, se dotó a los ejidos de La Magdalena Contreras y San Bernabé Ocotepec. ${ }^{75}$

\section{PARA TERMINAR}

Durante las primeras ocho décadas de vida de la joven nación, en estas serranías de las Cruces y el Ajusco, fue posible hallar más continuidades que cambios respecto a cuáles fueron y cómo se negociaron los derechos y la propiedad sobre áreas forestales de pueblos y haciendas. Estas permanencias estaban lejos de reflejar un escenario carente de conflictos; entre otras razones, porque el siglo XIX no fue estático ni en el país, ni en estos territorios. Las transformaciones principales se agolparon a partir de la restauración republicana de 1867, cuando finalizó una profunda guerra de intervención, pues a partir de entonces el grupo triunfante pudo empezar a concretar proyectos y leyes para formar

75 RAN, AGA, La Magdalena Contreras, Ampliación de ejidos, exp. 3 25/931 (3), fs. 102-105, y Percheron, Problemas agrarios, pp. 179, 184-186, 206, 214 y 217. Cabe señalar que estos montos tienen ligeras variaciones según las diferentes fuentes. 
la república liberal que tanto anhelaban. Este empuje político se conjuntó con transformaciones económicas y tecnológicas que llevaron a varios hacendados, así como a dueños de fábricas del textil y del papel, a utilizar de manera más intensiva aguas, maderas y carbón. Ello se aunó a la perspectiva gubernamental cada vez más "científica" del uso del bosque.

Costumbres y leyes pretéritas sobre bosques, montes y pastizales marcaron una persistencia relativa. Se fundamentaron en la permanencia de ciertas Leyes de Indias ya que, mientras no eran explícitamente derogadas, se mantenían en vigor. Más aún, las autoridades de toda jerarquía, así como pueblos y particulares, las seguían acostumbrando si así les convenía. Retenían en su memoria ciertos trozos que utilizaban como fuentes de legitimidad. En suma, conformar una cultura jurídica que se quería "moderna" con leyes positivas generales, puestas en práctica por individuos más que colectividades, fue un proceso largo y accidentado. $^{76}$

Vale la pena recapitular en torno a las argumentaciones. En el México independiente, el puntal con que los pueblos negociaron sus atribuciones forestales fueron títulos, mapas, lienzos, leyes y decretos coloniales, usos consuetudinarios, así como probar -o al menos alegar- que habían ejercido una posesión pacífica durante largo tiempo. ${ }^{77}$ También esgrimieron testimonios de factura paternalista y de economía moral, en esencia, que no era justo negar a leñadores, pastores y carboneros los recursos si estaba en juego su sobrevivencia. Un testimonio emblemático lo esgrimió San Nicolás al señalar que no podían quitarle dichos bienes dadas las condiciones por las que atravesaban después de que las tropas francesas habían incendiado sus chozas y pertenencias. En otras ocasiones, adoptaron la perspectiva de

${ }_{76}$ Véase la obra clásica de Grossi, Mitología jurídica.

77 El complejo tema de la definición y los derechos que amparaban las "posesiones" es una de las vetas historiográficas que están en busca de historiador. Para el Estado de México, véase Falcón, El jefe político, pp. 490-503. 
las autoridades: referir que la ciudad se perjudicaría si los pueblos dejaban de abastecer leña y carbón.

Desde luego que en el largo siglo xix no todos los reclamos fueron una prolongación de potestades antiguas. También se fundaron con base en la modernidad jurídica y política y apelaron a las instancias gubernamentales, lo que implicaba conocer sus valores y reglamentación aun cuando, en el porfiriato, esta última fue crecientemente restrictiva para los pueblos. Si corrían con suerte, los abogados, tinterillos y otros representantes de los actores colectivos, traducían sus preocupaciones al lenguaje legal adecuado, además de idear estrategias políticas y legales con probabilidades de éxito. ${ }^{78}$ En suma, en términos de la cultura de pueblos, de particulares y de autoridades, más que una transición a formas modernas de determinar la justicia, se dio una mezcla de razonamientos de antaño y nuevo cuño como mostró la aquí referida petición para litigar que San Nicolás Totolapan obtuvo en 1872.

Así con todo, hasta la década de 1920, convivieron casi los mismos pueblos y las mismas haciendas que se habían forjado desde la era colonial. Ciertamente hubo transformaciones de peso, como fue el empleo más intensivo e industrializado de maderas y carbón por parte de fincas, fábricas y probablemente de las mismas comunidades, la creciente mercantilización de los recursos, lo mismo que la introducción del ferrocarril a Cuernavaca. Pero ni todo ello, ni las leyes liberales que tendían a "perfeccionar" la propiedad privada, significaron un parteaguas definitivo. Sobra decir que entre pueblos y haciendas hubo, además de conflictividad, otras formas de convivencia: relaciones laborales y hasta la necesidad de enfrentar retos comunes, tal cual fueron las guerras y epidemias, o cuando se disponía que todos por igual dejasen de cortar árboles, pastar ganado o fabricar carbón.

78 Guerrero, "El proceso”. 
Los paliativos y mediaciones gubernamentales están, casi inevitablemente, sobrerrepresentados en los archivos que fundamentaron este texto. Sin embargo, estas querellas son preciosas para los historiadores porque abren una ventana al pasado. Las demandas, quejas, litigios, entre otros recursos ante el poder ejecutivo y de justicia, muestran el peso de la maquinaria gubernamental para detener posibles violencias, "comprar tiempo", negociar o, al menos, dar una semblanza de arreglo. No debe creerse que, en este entresijo burocrático, los gobernantes -incluso los porfiristas- fungieron como una burda agencia en apoyo de los hacendados. En no pocas ocasiones respaldaron las demandas de los pueblos. Los mismos de San Nicolás lo reconocieron en 1923 en su solicitud de ejido: "El gobierno del General Díaz [...] a pesar de ser latifundista recalcitrante y protector decidido de la clase rica, siempre respetó los derechos de San Nicolás Totolapan en el pleito que sigue contra la Hacienda Eslava". ${ }^{79}$ Era una presión significativa para los revolucionarios, pues de no dotarlos, podrían quedar peor ante el pueblo que el propio “viejo régimen”. Pero ello no sucedió: recibieron tierras de su antigua enemiga.

Por otro lado, durante siglos, además de la lucha sempiterna por estos territorios, hay constancias claras del enojo de los pobladores por los abusos y malos tratos de los administradores de haciendas muchas veces en connivencia de jueces de paz y jefes de policía. Algunos de estos personajes, incluso, desempeñaban varios papeles a la vez. Los roces cotidianos que tenían tales personajes con la gente del común fueron fundamentales para consolidar el odio popular.

En suma, la conflictividad entre pueblos y haciendas era multifactorial: problemas en torno al bosque, monte y pastizales. Como se ha mostrado, otras razones igual de significativas

79 RAN, AGA, San Nicolás Totolapan, Restitución de ejidos, 24/937 (17), fs. 267-268, 8 de octubre de 1923. 
estribaban en los agravios morales. Aun cuando aquí no fueron tratados, otros motivos estructurales del descontento eran la utilización, calidad y propiedad del agua, así como las condiciones de vida de los muchos habitantes que eran obreros del textil y del papel.

Ahora bien, ¿qué tan representativo es este caso para arrojar luz respecto a los derechos sobre bosques a lo largo y ancho del país? ¿Qué tan común fue que, durante casi la primera centuria del México independiente, pueblos y haciendas lograran cierto equilibrio en sus facultades sobre los territorios forestales? ¿Cómo explicar la ausencia relativa de rebeliones y tumultos, al menos hasta 1911? ¿Cómo conjugar estas querellas por la leña, los pastos y el carbón con las disputas, acaso más frecuentes, por las aguas y otros tipos de terrenos? ¿Cómo se influían las tensiones agrarias con las que se derivaban de las estrictas relaciones laborales en haciendas y fábricas?

Este tipo de preguntas fascinantes carecen de una respuesta definitiva por su carácter hipotético y por los muchos huecos historiográficos a llenar. Existen ejemplos análogos en donde los equilibrios en torno a los bosques no acabaron de romperse, en especial en territorios alejados de la modernización económica y de comunicaciones, pues el aislamiento inhibía la codicia por los recursos naturales. Sin embargo, asumo que la explicación de por qué estos pueblos lograron conservar parte de sus usos forestales debe estar en otra parte, puesto que en el porfiriato estos territorios fueron surcados por el tren a Cuernavaca, además de que desde mediados del siglo xix las antiguas fábricas apostadas sobre el río aumentaron su control sobre aguas y bosques.

Al mismo tiempo, hay que recalcar que este caso de estudio solo muestra una cara de la moneda ya que, en otros rincones del país, hay paradigmas dispares en 180 grados. El caso más sonado es la catástrofe ecológica en la región de Chalco, Estado de México -no muy lejos de Contreras y, por cierto, fuertemente 
zapatista-, en donde, a lo largo del siglo xIX, varias comunidades perdieron aguas -incluso se desecó parte de este extenso lago en beneficio de unos hacendados-, tierras y bosques. Ahí, la extensa y moderna fábrica de papel San Rafael consumía enormes cantidades de recursos naturales, lo que llevó a profundos desajustes ecológicos y de sobrevivencia. En respuesta a la pérdida de bienes y de futuro, ciertas comunidades ribereñas montaron rebeliones (1867-1868), revueltas, motines, resistencias, presiones colectivas, litigios, demandas y todo tipo de argucias. ${ }^{80}$

Entonces, el apoyo que buen número de estos pueblos brindó a los zapatistas obliga a formular otras interrogantes aún sin respuesta: ¿la relativa "paz" que pareció reinar durante el porfiriato sería una mera apariencia, un statu quo superficial que explotaría en mil pedazos al soltarse los lazos que lo mantenían atado?, o bien, ¿el apoyo a los insurrectos estribó en su capacidad para montarse sobre la ola rebelde que, eventualmente, los llevaría a ser propietarios de enormes recursos forestales, que siempre habían reclamado, en detrimento de las haciendas vecinas, sus antiguos contrincantes? Probablemente se trata de una mezcla de ambas explicaciones.

Es aquí donde la idea de las "corrientes subterráneas" completa el panorama y ayuda a difuminar esa condición un tanto "estática" de la continuidad relativa desde la era colonial hasta la revolución mexicana. En efecto, numerosas tensiones y agravios habían quedado subsumidos bajo la imagen de tranquilidad que emana de los repositorios gubernamentales. Las rebeliones iniciadas en 1910-1911, en especial las agraristas, hicieron visibles las grietas profundas que desde hacía mucho oponían a actores colectivos con privados. En dichas corrientes -como espero haya quedado demostrado- eran tan significativas las querellas por el bosque como los odios personales contra varias figuras de autoridad en sus niveles más bajos, así como en contra

${ }^{80}$ El libro clásico sobre esta región es ANAYA, Rebelión y revolución. 
de los encargados del orden y del día a día en las haciendas. En fin, los derechos de los pueblos y las haciendas en torno a los recursos forestales fueron, en todo México, una madeja de contradicciones y tonos de gris.

\section{SIGLAS Y REFERENCIAS}

AGN Archivo General de la Nación, fondo Gobernación, Periodo Revolucionario, sección Correspondencia con Secretarias, serie Secretaría de Relaciones Exteriores, Ciudad de México, México.

AGN fondo Gobernación, sección Segundo Imperio, Tranquilidad Pública, Prefecturas del Valle de México y Toluca

AGN Archivo del Tribunal Superior de Justicia del Distrito Federal, Siglo XIX

AGN fondo Genovero de la $\mathrm{O}$

AGN fondo Emiliano Zapata

AGN fondo Fomento, sección Bosques

AHCM Archivo Histórico de la Ciudad de México, fondo Municipalidades, sección Tlalpan, serie Gobernación, sección San Ángel, serie Tierras, Ciudad de México, México.

AHDN Archivo Histórico de la Secretaría de la Defensa Nacional, Ciudad de México, México.

RAN, AGA Registro Agrario Nacional, Archivo General Agrario, San Nicolás Totolapan, La Magdalena Contreras, Ciudad de México, México.

Almazán, Marco Antonio, "Usos, perspectivas y conflictos por los recursos forestales en los pueblos de montaña (Nevado de Toluca) durante el porfiriato, 1876-1911", tesis de maestría en antropología social, Centro de Investigaciones y Estudios Superiores en Antropología Social, 2011.

Almeida-Leñero, Lucía, Mariana Nava, Alya Ramos, Mónica Espinosa, María de Jesús ORDOÑEZ y Julieta JujnovsKY, "Servicios ecosistémicos en la cuenca del río Magdalena, Distrito Federal, México”, en Gaceta Ecológica, 84-85 (jul.-dic. 2007), pp. 53-64.

Anaya Pérez, Marco Antonio, Rebelión y revolución en Chalco-Amecameca, Estado de México, 1821-1921, México, Instituto Nacional de Estudios Históricos de la Revolución Mexicana, Universidad Autónoma de Chapingo, 1997, 2 volúmenes. 
Ávila-Akenberg, Víctor, "Forest quality in the southwest of Mexico City. Assessment toward ecological restoration of ecosystem services", tesis de doctorado, Freiburg, Alemania, Institut für Landspfegle-Universität Freiburg, 2010.

Ávila Espinosa, Felipe, Los orígenes del zapatismo, México, El Colegio de México, Universidad Nacional Autónoma de México, 2001.

Ávila Espinosa, Felipe, Breve historia del zapatismo, México, Critica, 2018.

Barbosa Cruz, Mario (coord.), Memorias del poniente II: Historias de sus pueblos, barrios y colonias. Segundo concurso de historias de pueblos, barrios y colonias del poniente de la Ciudad de México, México, Universidad Autónoma Metropolitana-Cuajimalpa, 2016.

Barcos, María Fernanda, Sol Lanteri y Daniela Marino (dirs.), Tierra, agua y monte. Estudios sobre derechos de propiedad en América, Europa y África (siglos XIX Y XX), Buenos Aires, Teseo, 2017.

Blázquez, Carmen, Carlos Contreras y Sonia Pérez Toledo (coords.), Población y estructura urbana en México, siglos XVIII y XIX, México, Gobierno de Veracruz, Universidad Veracruzana, 1996.

Bonilla, Heraclio y Amado A. Guerrero (eds.), Los pueblos campesinos de las Américas. Etnicidad, cultura e historia en el siglo XIX, Colombia, Universidad Industrial de Santander, 1996.

Buve, Raymond, "Caciques, vecinos, autoridades y la privatización de los terrenos comunales: un hierro candente en el México de la república restaurada y el porfiriato”, en Bonilla y Guerrero (eds.), 1996, pp. 25-41.

Buve, Raymond y Romana Falcón (coords.), Pueblos en tiempos de guerra. La formación de la nación en México, Argentina y Brasil (1800-1920), México, El Colegio de México, 2017.

Camacho de la Rosa, Gerardo, Raíz y razón de Totolapan. El drama de la guerra zapatista, México, Gobierno del Distrito Federal, Secretaría de Desarrollo Social, Centro de Estudios Antropológicos, Científicos, Artísticos, Tradicionales y Lingüísticos “Ce-Acatl”, 2007.

Carrillo Trueba, César, El pedregal de San Ángel, México, Universidad Nacional Autónoma de México, 1995. 
Escobar, Antonio, Romana Falcón y Raymond Buve (comps.), Pueblos, comunidades y municipios frente a los proyectos modernizadores en América Latina, siglo XIX, México, Centro de Estudios y Documentación Latinoamericanos, El Colegio de San Luis, 2002.

FaLcón, Romana, "El Estado liberal ante las rebeliones populares. México, 1867-1876”, en Historia Mexicana, LIv: 4 (216) (abr.-jun. 2005), pp. 973-1048.

Falcón, Romana, "Desamortización a ras de suelo, ¿el lado oculto del despojo? México en la segunda mitad del siglo xix", en Ponce y Pérez Rosales (coords.), 2009, pp. 59-85.

Falcón, Romana, El jefe político. Un dominio negociado en el mundo rural del Estado de México, 1856-1911, México, El Colegio de México, El Colegio de Michoacán, Centro de Investigaciones y Estudios Superiores en Antropología Social, 2015.

Falcón, Romana, “Tiempos de guerra. Los usos de la violencia para ratificar y rectificar los derechos sobre los recursos naturales en el Estado de México, 1850-1870”, en Buve y Falcón (coords.), 2017, pp. 159-188.

Galván Rivera, Mariano, Ordenanzas de tierras y aguas, edición facsimilar de 1868 con presentación de Teresa Rojas Rabiela, México, Registro Agrario Nacional, Centro de Investigaciones y Estudios Superiores en Antropología Social, 1988.

Gayosso Argüello, Mariana Berenice, "Catálogo de la sección de tranquilidad pública del fondo Gobernación, sección Segundo Imperio del Archivo General de la Nación, correspondiente a las prefecturas del Valle de México y Toluca", tesis de licenciatura, México, Universidad Nacional Autónoma de México, 2003, 2 volúmenes.

Genovese, Eugene, Roll Jordan Roll: The World the Slaves Made, Nueva York, Pantheon Books, 1979.

GonzÁlez Navarro, Moisés, "Las huelgas textiles en el porfiriato", en Historia Mexicana, vi: 2 (22) (oct.-dic. 1956), pp. 201-216.

Grossi, Paolo, Mitología jurídica de la modernidad, Madrid, Trotta, 2003.

Guerrero, Andrés, "El proceso de identificación: sentido común ciudadano, ventriloquia y transescritura”, en Escobar, FALCón y Buve (comps.), 2002, pp. 29-63. 
Jujnovsky, Julieta, Laura Galván y Marisa Mazari-Hiriart, “Zonas Protectoras Forestales: el caso de los bosques de la Cañada de Contreras, Distrito Federal”, en Investigación Ambiental. Ciencia y Política Pública, 5: 2 (2013), pp. 65-75.

LAU J., Ana, “Tlalpam: una nueva organización administrativa, 1824-1903”, en Blázquez, Contreras Pérez y Perez Toledo (coords.), 1996, pp. 301-320.

Levario Acosta, Beatriz, "San Bernabé Ocotepec, nacimiento de una comunidad: su identidad cultural y política”, tesis de licenciatura, Universidad Autónoma Metropolitana-Iztapalapa, 2000.

Ley de organización politica y municipal del Distrito Federal, México, Imprenta del Gobierno Federal en el Ex-Arzobispado, 27 de marzo de 1903.

Lira, Andrés, "Los bosques en el virreinato, apuntes sobre la visión política de un problema”, en Relaciones, 41 (1990), pp. 117-127.

López Romero, Edmundo, "La llegada de los zapatistas a Magdalena Contreras. Historia de una ilusión”, en BARBosa Cruz (coord.), 2016, pp. 243-252.

Magaña, Gildardo, Emiliano Zapata y el agrarismo en México, tomo II, México, Ruta, 1911, 2 tomos.

Marino, Daniela, "La desamortización de las tierras de los pueblos (centro de México, siglo xix). Balance historiográfico y fuentes para su estudio”, en América Latina en la Historia Económica. Boletín de Fuentes, 16 (jul.-dic. 2001), pp. 33-43.

Payno, Manuel, "Bosques y arbolados", en Boletín de la Sociedad Mexicana de Geografía y Estadística, tomo II, Segunda época (1870), pp. 77-91.

Percheron, Nicole, Problemas agrarios del Ajusco. Siete comunidades agrarias de la periferia de México (siglos XVI-XX), México, Centro de Estudios Mexicanos y Centroamericanos, Sederec, Ambassade de France au Mexique, 2008.

Ponce, María Eugenia y Laura Pérez Rosales (coords.), El oficio de una vida. Raymond Buve, un historiador mexicanista, México, Universidad Iberoamericana, 2009. 
Ramos Cruz, Jovita Elena, "Formas de conflicto ambiental. El caso de los montes y las aguas en la Municipalidad de San Ángel, Distrito Federal (18701910)", en Barcos, Lanteri y Marino (dirs.), 2017, pp. 33-70.

Reyna, María del Carmen, Haciendas en el sur de la Ciudad de México, México, Instituto Nacional de Antropología e Historia, Gobierno del Distrito Federal, 1997.

Ruiz Medrano, Ethelia, Mexico's Indigenous Communities. Their Lands and Histories, 1500-2010, Boulder, Colorado, University Press of Colorado, 2010.

Sales Colín, Jesús, Miguel Ángel Flores y Leticia Contreras, "La importancia de rescatar, preservar, mantener y cuidar la cuenca del Río Magdalena, Distrito Federal”, en Revista del Centro de Investigación, 5: 19 (jul.-dic. 2002), pp. 5-11.

Trujillo Bolio, Mario, Operarios fabriles en el Valle de México, 1864-1884. Espacio, trabajo, protesta y cultura obrera, México, Centro de Investigaciones y Estudios Superiores en Antropología Social, El Colegio de México, 1997.

Tutino, John, De la insurrección a la revolución en México. Las bases sociales de la violencia agraria, 1750-1940, México, Ediciones Era, 1990. 